\title{
Effects of Dietary Immunomodulation on Parasite Load in Commercial Crossbred Lambs
}

\author{
Rebecca Christine Price \\ West Virginia University
}

Follow this and additional works at: https://researchrepository.wvu.edu/etd

\section{Recommended Citation}

Price, Rebecca Christine, "Effects of Dietary Immunomodulation on Parasite Load in Commercial Crossbred Lambs" (2014). Graduate Theses, Dissertations, and Problem Reports. 604.

https://researchrepository.wvu.edu/etd/604

This Thesis is protected by copyright and/or related rights. It has been brought to you by the The Research Repository @ WVU with permission from the rights-holder(s). You are free to use this Thesis in any way that is permitted by the copyright and related rights legislation that applies to your use. For other uses you must obtain permission from the rights-holder(s) directly, unless additional rights are indicated by a Creative Commons license in the record and/ or on the work itself. This Thesis has been accepted for inclusion in WVU Graduate Theses, Dissertations, and Problem Reports collection by an authorized administrator of The Research Repository @ WVU. For more information, please contact researchrepository@mail.wvu.edu. 


\title{
Effects of Dietary Immunomodulation on Parasite Load in Commercial
} Crossbred Lambs

\author{
Rebecca Christine Price
}

Thesis submitted to the Davis College of Agriculture, Natural Resources and Design at West Virginia University in partial fulfillment of the requirements for the degree of

$$
\text { Master of Science in Animal Physiology }
$$

Scott A. Bowdridge, Ph.D, Chair

Sangita V. Jalukar, Ph.D.

Margaret A. Minch, DVM

Division of Animal and Nutritional Sciences

Morgantown, West Virginia

2014

Keywords: Haemonchus contortus; Celmanax®; Immunomodulation

Copyright 2014 Rebecca Christine Price 


\begin{abstract}
Effects of Dietary Immunomodulation on Parasite Load in Commercial Crossbred Lambs

\section{Rebecca Christine Price}

Multidrug resistant gastrointestinal nematodes have left sheep producers with little options to control the detrimental effects of parasitism on their flocks. Immunomodulation has been used in many autoimmune diseases in an effort to downregulate the immune system and alleviate pathology. However, upregulation of immune responses by use of dietary immunosaccharides may allow parasite susceptible sheep to clear a Haemonchus contortus infection. To test this hypothesis, Dorset-Texel lambs were fed a ration including Celmanax® at $1 \mathrm{~g} / \mathrm{hd} /$ day for one week prior to receiving an experimental infection of $10,000 \mathrm{~L}_{3}$ stage $H$. contortus larvae; which continued until the completion of the study. Increases in eosinophils and mannose binding lectin- $C$ were observed in lambs receiving Celmanax ${ }^{\circledR}$ indicating upregulation of innate immune responses. Celmanax ${ }^{\circledR}$ alone reduced TNF- $\alpha$ mRNA within fundic mucosa, aiding in the polarization of a $\mathrm{TH}_{\mathrm{H}}$ immune response. Supplementation with Celmanax ${ }^{\circledR}$ did not have any effects on worm burden or fecal egg count (FEC) in infected lambs. These results indicate that Celmanax® has immunomodulatory properties, but may not have absolute effects on clearing helminth infections in Texel crossbred lambs.
\end{abstract}




\section{Acknowledgements}

I would like to start out by thanking my advisor Dr. Scott Bowdridge. I will be forever bettered from the opportunity he gave me by allowing me to come to WVU. He has always offered words of wisdom on all subjects from my project to my future career path. I have yet to find a topic he knows nothing about. From the start he has pushed me to be a better critical thinker and view all data as a key piece of a puzzle.

I have to thank all my lab mates for their help and encouragement: Rush Holt, Megan Graham, Jesica Jacobs, Karen Sommers, and Crista Crawford. If it were not for them, my last two years would have been much more stressful. Everyone within the Animal and Nutritional Sciences has made my stay here that much more memorable. I have never been in a place where everyone is so willing to help out a fellow colleague in times of need.

I need to thank my family for their continued support. My mother, Joanne Price, has never once wavered in the fact that she is proud of my accomplishments and loves me no matter what. She always has helped me anyway she knows how and I will forever be honored to call her my mom. Thank you Aunt Terry for understanding why it was imperative for me to be away from the farm for such a long time.

Many thanks to Vi-Cor for funding my research. I would not have been able to conduct such thorough research without it.

Finally, I need to thank Staton Klein. He has always been there to give advice. I have no idea how I would have made it to this point without his constant love. 


\section{Table of Contents}

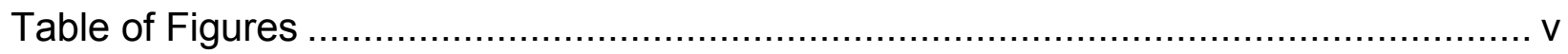

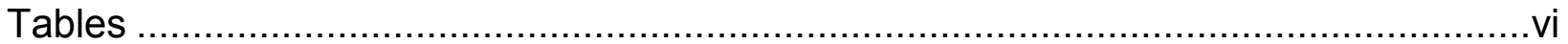

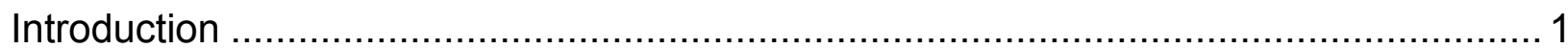

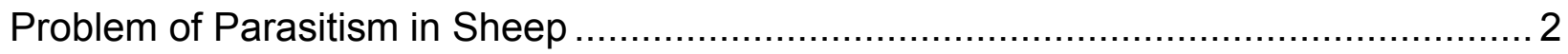

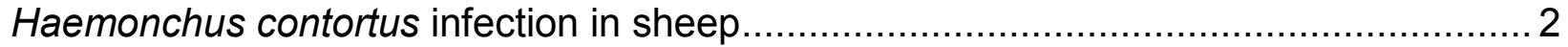

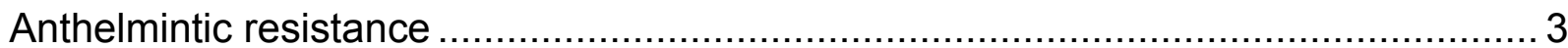

Parasite resistance among different breeds ....................................................... 4

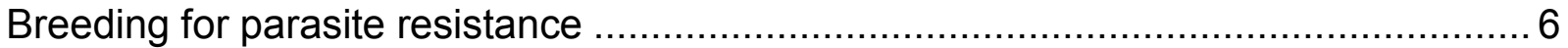

T-helper cell type 2 response to $H$. contortus...................................................... 7

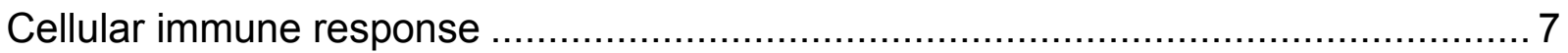

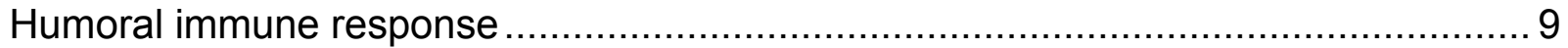

Immunomodulation of the Immune System ……................................................. 10

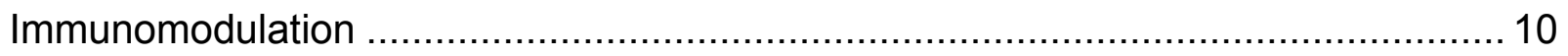

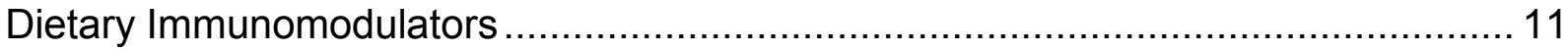

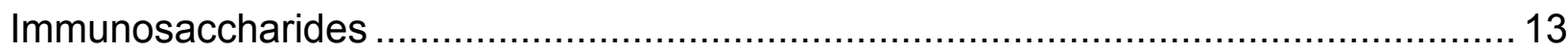

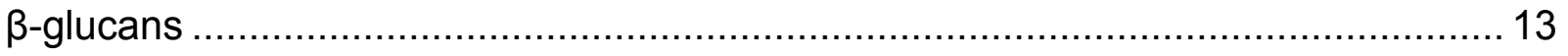

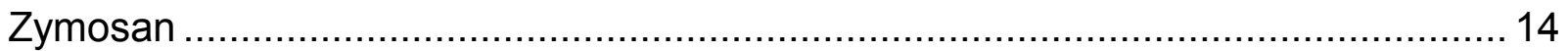

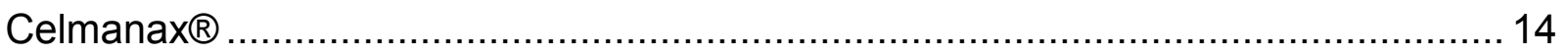

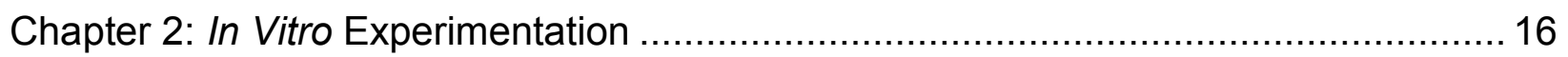

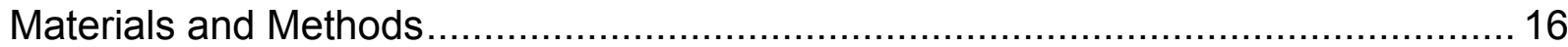

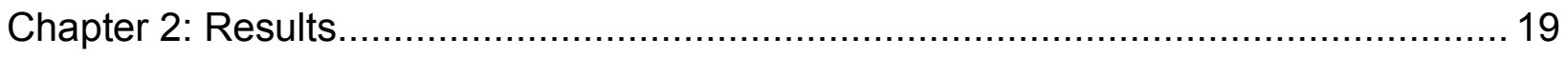

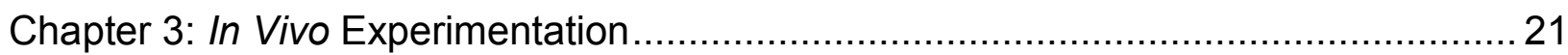

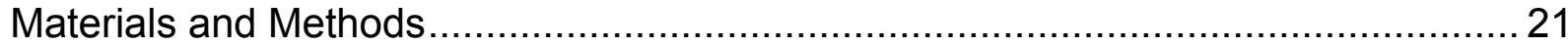

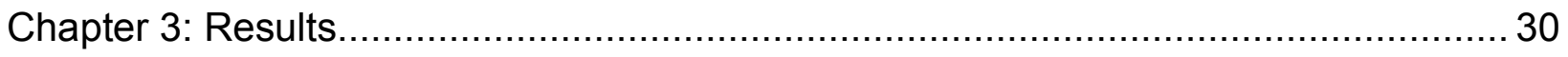

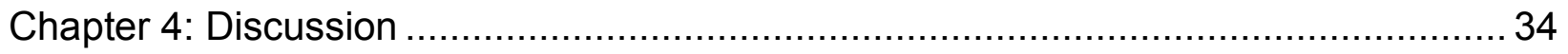

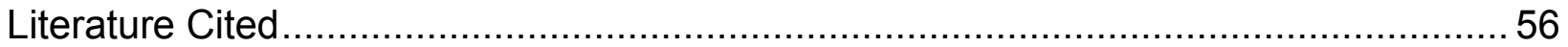




\section{Table of Figures}

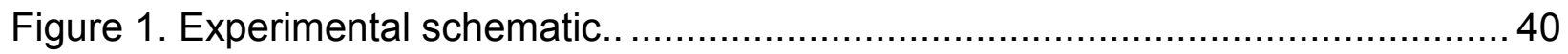

Figure 2. Nitric Oxide of stimulated monocytes in vitro.......................................... 41

Figure 3. Arginase Activity of stimulated monocytes in vitro..................................... 42

Figure 4. Fecal egg count and worm burden during primary and challenge $H$. contortus

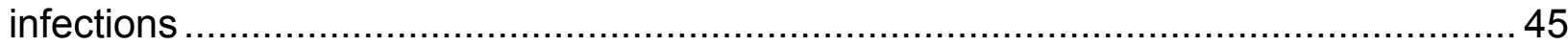

Figure 5. Packed cell volume and total WBC counts of lambs during primary and challenge $H$. contortus infections

Figure 6 . White blood cell differential counts during primary and challenge $H$. contortus infections

Figure 7. Eosinophil counts of lambs during primary and challenge $H$. contortus infections

Figure 8. Lymph node counts and weights during primary and challenge $H$. contortus infections.

Figure 9. Serum and mucus IgA during $H$. contortus infections.

Figure 10. Serum and antigen specific IgG production during a challenge $H$. contortus infection

Figure 11. Production of serum mannose binding lectin-C (MBL-C) during primary and challenge $H$. contortus infections.

Figure 12. TNF- $\alpha$ gene expression in the fundic mucosa during a challenge $H$. contortus infection. 


\section{Tables}

Table 1. Wool monocyte gene expression during in vitro experiment. ......................... 43

Table 2. Hair monocyte gene expression during in vitro experiment........................... 44

Table 3. Lymph node gene expression during primary and challenge $H$. contortus

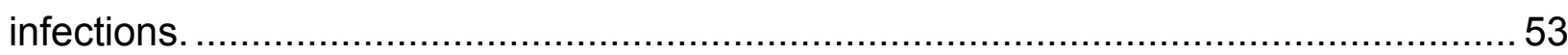

Table 4. Fundic mucosa gene expression during primary and challenge $H$. contortus

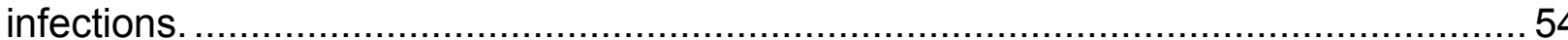




\section{Introduction}

Gastrointestinal parasites have a large negative effect on small ruminant production throughout the world. Wool, growth, and ultimately lamb yield are negatively affected by helminth infection if left untreated (Rowe et al., 1988; Datta et al., 1999). Years of unregimented treatment of helminth parasites has resulted in selection of worm populations with resistance to available dewormers. Some producers have utilized alternative parasite management strategies by incorporating hair-type breeds of sheep, known for their parasite resistance, into commercially desirable wool flocks.

Unfortunately, this integration results in decreased carcass sizes (Wildeus, 1997) and some increase in parasite resistance, but not complete resistance (Amarante et al., 1999).

Hair-type sheep are able to clear a parasite infection through early, robust immune responses. Increases of eosinophils, IgE, and $\mathrm{TH}_{\mathrm{H}}$ cytokines occur within the first few days after infection in St. Croix and Gulf Coast Native hair sheep (Bowdridge, 2009; Shakya et al., 2009). Alternatively, wool breeds are unable to mount and sustain an immune response that results in parasite clearance. No current strategy exists whereby immunityobserved in hair breeds can be effectively introgressed into wool breed sheep without loss of economically important traits. A potential solution to this problem is immunomodulation of wool breeds. This thesis proposes that the use of a dietary immunomodulator stimulates upregulation of immunity in wool sheep, potentially permitting the development of host protective immune responses during a helminth parasite infection. 


\section{Problem of Parasitism in Sheep}

\section{Haemonchus contortus infection in sheep}

When $H$. contortus $L_{3}$ infective stage larvae reach the host abomasum they mature into adults and use a lancet to facilitate blood feeding in the abomasum. It has been determined that one $H$. contortus adult removes approximately $0.08 \mathrm{~mL}$ of blood every day from their host (Baker, 1959). Clinical symptoms of haemonchosis include bottle jaw, due to loss of plasma protein and red blood cells; paleness of mucus membranes of the eyes, due to severe anemia; and sudden death (Bowman, 2009). Effects of $H$. contortus infection on the host are detrimental to economic small ruminant production as they reduce wool production, lamb growth, and lactation rates. Infection of merino wethers with $300 \mathrm{H}$. contortus larvae/kg of live weight resulted in reduced rumen fermentation and nitrogen absorption in the large intestine leading to reduction of essential amino acids and irreversible hypoproteinemia (Rowe et al., 1988). Low protein levels result in decreased lamb productivity. Protein supplementation for nine weeks post-weaning to infected crossbred lambs increased clean fleece yield and live weight gain when those lambs grazed naturally infected pastures (Datta et al., 1999). Ewes experience more detrimental effects from parasite infections during pregnancy and lactation. Infected ewes consuming the same amount of food as non-infected ewes had slightly lower weight gains during pregnancy. After parturition infected ewes continuously lost weight and produced significantly less milk compared to control ewes (Thomas and Ali, 1983). At one point clearing of a parasite infection to lessen economic loss was as simple as using anthelmintics belonging to the one of three classes of broad spectrum dewormers. 


\section{Anthelmintic resistance}

Three classes of broad spectrum anthelmintics currently available in the United States are benzimidazoles, imidathiazoles, and macrocyclic lactones. As early as 1964, $H$. contortus resistance to benzimidazoles was documented when a group of infected sheep receiving multiple doses of thiabendazole saw no decrease in fecal egg count (FEC) after the 4th treatment with dewormer (Drudge, 1964). Increased occurrence of this phenomenon resulted in availability of new anthelmintics. Imidathiazoles and tetrahydropyrimidines were first introduced in the late 1960's, and quickly thereafter reports of parasite resistance followed. Resistance to morantel tartrate was documented when efficacy fell to $75 \%$. Resistance of $H$. contortus to levamisole was predicted when an absence of a dose dependent effect on a laboratory strain of worms was observed (Le Jambre, 1976). Development of resistance to macrocyclic latones (avermectins and milbemycins) occurred soon after their development. In South Africa, Merino sheep were infected with five anthelmintic resistant strains of $H$. contortus and subsequently treated with ivermectin. The authors reported that four strains were resistant to ivermectin and $72.5 \%$ worm burden reduction was the greatest of the four strains (van Wyk and Malan, 1988). These data indicate that populations of $H$. contortus are resistant to at least one class of anthelmintics available, but many strains exhibit multiple-drug resistance (MDR). Determination of anthelmintic resistance of larvae hatched from feces gathered from 46 sheep and goat farms located in the southeastern United States revealed $48 \%$ of farms surveyed had nematode populations resistant to all three classes of anthelmintics (Howell et al., 2008). In the absence of efficacious dewormers, incorporation of multiple grazing strategies to manage 
parasitism have not had the combined effect of effective anthelmintics. The control strategy that has shown the most promise is the utilization of parasite-resistant breeds of sheep.

\section{Parasite resistance among different breeds}

Utilizing breeds of sheep resistant to $H$. contortus has proven more effective than avoidance of parasitism through pasture rotation. Some hair type sheep have been naturally selected for helminth resistance which is thought to be a result of persistent infection pressures. Soay sheep located on Scotland's Hirta Island revealed significant variation between the frequency of OLADRB3 alleles (MHC alleles associated with resistance to juvenile parasitic nematodes) and fluctuating Teladorsagia circumcincta numbers (Charbonnel and Pemberton, 2005). Sheep existing under persistent pressure from parasites undergo natural selection of individuals with mechanisms to cope with increased parasite infection, ultimately leading to an entire population resistant to helminths. This is indicated by the additive genetic variance for parasite resistance seen in Soay sheep, thus implying response to selection (Coltman et al., 2001). Tropical climates provide optimal environments for larval development, thus sheep existing in these climates may have evolved increased parasite resistance, one such breed is the St. Croix.

Many studies have compared St. Croix hair sheep to various wool breed sheep. When grazed on $H$. contortus infected pastures, St. Croix lambs generate a lower FEC and have a $99 \%$ lower worm burden in the gut when compared to Dorset (wool) lambs grazed under the same conditions, indicating resistance to adult worm establishment (Gamble and Zajac, 1992a). Similar results are documented during experimental 
infections, whereby, St. Croix lambs inoculated with $500 \mathrm{~L}_{3} \mathrm{H}$. contortus larvae over a period of five days shed significantly lower eggs in their feces compared to their Dorset counterparts (Gamble and Zajac, 1992b).

Other breeds of hair sheep exhibit $H$. contortus resistance as evidenced by lower FEC and mortality rates, and higher PCV reported during both natural and experimental H. contortus infections. Mugambi et al. (1997) found that during a challenge infection with 10,000 H. contortus L3 stage larvae, Red Maasai sheep had lower FEC and maintained a higher PCV than Dorper and Blackheaded Somali sheep. During primary and challenge infections of $10,000 \mathrm{H}$. contortus $\mathrm{L}_{3}$ stage larvae, Barbados Black Belly sheep had a delay in FEC and a lower egg output compared to parasite susceptible breeds, in addition to lower worm burdens, female worms were smaller along with reduced number eggs in utero (Terefe et al., 2007). Gulf Coast Native sheep grazed together with and separately from Suffolk sheep on naturally infected pastures over eight years always had significantly lower FEC (Miller et al., 1998). Parasite-resistance of hair type sheep have led to an increased interest in their utilization for improving parasite resistance in commercial sheep flocks, in light of failing anthelmintics.

Maximizing productivity of sheep grazed on pasture was the impetus for incorporating hair sheep in crossbreeding programs. Crossbreeding parasite resistant breeds with parasite susceptible breeds result in generation of offspring with intermediate phenotypic parasite resistance. Using FEC as a measure of parasite resistance, F1 crossbred lambs (Florida Native X Rambouillet) were more resistant to gastrointestinal nematode infection than Rambouillet lambs (Amarante et al., 1999). Despite improvements in parasite resistance, crossbred lambs lack many traits that 
affect productivity. Lack of a wool crop and carcass yield make this an economically poor option for incorporating parasite resistance into a flock.Growth rates, carcasses, and longissimus muscle area of hair-type lambs are consistently lower than wool breeds (Wildeus, 1997). Dorset sheep produce larger ribeye area and lower amounts of KPH fat than St. Croix sheep, leading to more desirable carcass yields (Horton and Burgher, 1992). Therefore, the incorporation of parasite resistant hair sheep becomes difficult while maintaining economically important traits. Thus, emphasis has been placed on selectivity within breeds for parasite resistance.

\section{Breeding for parasite resistance}

Improving parasite resistance of commercially acceptable sheep has relied on selecting individuals for reduced FEC. The main indicator of nematode resistance used is FEC (Gruner et al., 2004) and due to its high heritability is most selected upon (Bishop and Morris, 2007). Selection based on one FEC taken at a single time point in an animal's lifetime was once used to predict lifetime performance, but in recent years has since been changed to multiple sampling periods around weaning (NSIP, 2004). Varying environmental factors such as humidity, rainfall, and temperature affect larval hatching leading to fluctuations of host fecal egg output. Regardless, improving resistance comes at a cost of other fitness components. Higher resistance, based on low FEC, can lead to diversion of nutrients for weight gain to immune responses.

Flocks selected for lower FEC have higher circulating lgE levels when experiencing a challenge nematode infection leading to increases of inflammatory cells (Shaw et al., 1999), possibly causing reductions in weight gain. Inflammatory cytokines induce anorexia and muscle wasting in animals. In broiler chickens, injections of IL-1 lowered 
feed intake and feed utilization efficiency, which lead to decreases in daily gain (Klasing et al., 1987). Mice injected daily with cachectin (TNF- $\alpha$ ) decreased their food intake resulting in reductions in body mass (Cerami, 1985). Incubation of skeletal muscle with IL-1 increases protein degradation (Klasing et al., 1987).

Parasite resistance clearly has a direct link with immune responses. Quantitative trait loci (QTL) analysis have revealed that Romney sheep selected for low FEC had significant upregulation of interferon gamma (IFN-ץ) regions on chromosome 3 (Paterson, 2001). Microarray analysis of parasite resistance lambs resulted in observation of increased expression of MHC class II genes compared to susceptible lambs (Diez-Tascón et al., 2005). Upregulation of these particular genes point towards the type of immune response mounted against parasitic nematodes by the host.

\section{T-helper cell type 2 response to $H$. contortus}

\section{Cellular immune response}

Hair breeds resistant to helminth parasites rely on a potent immune response early during infection. Immune responses generated against both larval and adult stages are classified as T-helper cell type $2\left(\mathrm{TH}_{\mathrm{H}}\right)$ mediated responses with noticeable changes in cell recruitment to abomasal tissue as early as days $3,7,15$, and 28 post infection (Lacroux et al., 2006). It is critical during these first few days following larvae ingestion for the host to mount a robust immune response toward larvae in the abomasum to prevent the establishment of fecund adults. Antigens present on the surface of $\mathrm{L}_{3}$ and $\mathrm{L}_{4}$ (Balic et al., 2003) larvae may provide a target for host immunity. Recognition of parasite antigens by innate immune cells initiates the cascade of events for proper immune responses. Dendritic cell (DC) and macrophage populations in 
mucosa become activated by the presence of parasitic larvae migrating to their tissue niche. Intranasal chitin administration to macrophage depleted mice resulted in a significant decrease in eosinophil recruitment to the lungs, indicating macrophages act as chitin sensors (Reese et al., 2007). Adoptive transfer of mice with Nippostrongylus brasiliensis excretory/secretory antigen (NES) pulsed DCs resulted in DC activation and a $T_{H} 2$ skewed response (Balic et al., 2004). Once activated DC migrate to lymphoid tissue, they present processed parasite antigen on their surfaces leading to stimulation of T- and B-cells. Challenge infection of St. Croix and Dorset crossbred lambs with $10,000 \mathrm{~L}_{3} H$. contortus larvae revealed a considerable increase of abomasal lymph node weights indicating greater expansion of B-cells and T-cells at the site of infection in St. Croix lambs (Bowdridge, 2009). T-cells signal to innate immune cells to migrate to the site of infection and exert their effects. Eosinophils, mast cells, and neutrophils are continuously present in the abomasal fundic mucosa at significantly higher levels in Gulf Coast Native lambs compared to Suffolk lambs on day 35 post infection (Shakya et al., 2009). These results indicate that the Suffolk lambs are unable to produce a prolonged cell-mediated immune response to $H$. contortus adults, resulting in little generation of protective immunity and parasite susceptibility.

Alternative activation of macrophages is associated with helminth infection and allergic responses. In contrast to classically activated macrophages, alternatively activate macrophages (AAM) are responsible for wound repair and anti-helminth immunity (Anthony et al., 2006). During a challenge infection, AAM are recruited to the site of infection by T-cells and produce arginase to convert L-arginine into L-ornithine and other polyamines, which are needed for tissue remodeling (Gordon, 2003). Recent 
studies have hypothesized that arginase-producing AAM may contribute to possible protective immunity against helminths as well. Heligmosomoides polygyrus larvae cocultured with L-ornithine and polyamines reduced larval movement (Esser-von Bieren et al., 2013). Alternatively activated macrophages possess capabilities to alter host immunity whereby host protection is impaired by reducing inflammation as a result of tissue damage (Reyes and Terrazas, 2007). Activation of AAM is reliant upon the proper cytokine signaling, this environment generated by $\mathrm{T}_{\mathrm{H}} 2$ cells in response to parasitic nematodes.

\section{Humoral immune response}

A $T_{H} 2$ response is characterized by cytokines produced during $T$-cell responses. Interleukins $-4,-5,-10$, and -13 are the main cytokines produced by activated $T_{H} 2$ cells (Tizard, 2013). These cytokines promote B-cell growth and differentiation, and activate granulocytes. Differentiated B-cells during a parasitic nematode infection produce increased amounts of immunoglobulins (Ig) A, E, and G. Abomasal mucus had significantly higher IgA levels early in the challenge infection at days 7 and 15 post infection, compared to sheep that received a primary infection (Lacroux et al., 2006). Systemic IgE levels in parasite resistant sheep significantly increased from day 10 through day 42 post infection, whereas parasite susceptible sheep IgE levels remained at base levels (Shakya et al., 2009). Elevation of IgE levels causes type I hypersensitivity, which is reflected by increased basophil, eosinophil, and mast cell migration to the site of parasitic infection. Lymphatic, antigen-specific IgG1 and IgG2 levels were found to be higher during a challenge infection in both resistant and susceptible sheep (Pernthaner et al., 2006). Reoccurring literature indicate that 
parasite-resistant sheep mount a more potent $\mathrm{T}_{\mathrm{H}} 2$ response to helminths compared to wool breeds. A mechanism that could improve immunity of wool-type sheep may allow them to clear a $H$. contortus infection.

\section{Immunomodulation of the Immune System}

\section{Immunomodulation}

Immunomodulation can be defined as either a reduction or upregulation of the immune system. The majority of immunomodulatory techniques are aimed towards downregulation of immune-mediated disorders resulting in chronic inflammation, such as those involved in autoimmunity. Murine multiple sclerosis models dosed with Schistosoma mansoni ova resulted in a delay in clinical symptoms by influence of the cytokine environment from a $T_{H} 1$ chronic immune response to a $T_{H} 2$ (Sewell et al., 2003). The $\alpha_{4} \beta_{7}$ integrin antibody, MLN02, administrated to ulcerative colitis patients resulted in selective blocking of activated memory T-cells; resulting in greater remission of patients compared to controls (Feagan et al., 2005). Activation of Toll-like Receptors $-3 \&-7$ through injections of poly I:C or R-848 resulted in protection of mice from experimental asthma development (Sel et al., 2007).

In situations where the immune system does not respond to a pathogen, amplification of responses can be induced with the use of immunostimulants. Lipopolysaccharide and Propionibacterium acnes injections given for one week after $H$. contortus infection increased circulating eosinophils and lymphocytes while decreasing FEC (Abel et al., 2009). Vaccines are common immunomodulators and several have been developed in an effort to increase recognition and expulsion of $H$. contortus. Texel sheep immunized with excretory/secretory products from $H$. contortus $L_{3}$ stage larvae, 
followed by experimental infection had reduced FEC and worm counts along with an increase of mast cells in abomasal tissue and elevated antigen specific antibodies (Schallig et al., 1997). Membrane protein-derived antigen (H11) from adult $H$. contortus injected into Merino ewes resulted in significantly lower FEC with non-pregnant ewes having the lowest FEC. Additionally, maternal transfer of antigen specific antibodies significantly lowered FEC in lambs from vaccinated dams (Andrews et al., 1995). Dietary immunomodulators appeal to producers as they may be a method to easily modulate immune responses.

\section{Dietary Immunomodulators}

Efforts to modulate immune responses towards gastrointestinal parasites in sheep must have practical approach to delivery. Dietary supplementation is the easiest method of administering immunomodulators to a large flock. Many anti-parasitic substances have been utilized in this manner. Forages containing condensed tannins (CT), which are plant metabolites with the ability to increase protein availability in the small intestine (Mueller-Harvey and McAllan, 1992), could cause heightened immune responses in the host. Young goats administered condensed tannin forages during Trichostrongylus colubriformis and Teladorsagia circumcincta infections had higher eosinophils and mast cells in the small intestines along with decreases in female worm fecundity (Paolini et al., 2003). High tannin forages are unable to compete with many clover and grass species, therefore herbicides must be applied to pastures aiding establishment (Aerts, 1999). A more effective method of dietary immunomodulation may be to incorporate supplements into concentrate diets as opposed to relying on forages. Copper is critical for both innate and acquired immune functions. Deficiencies 
result in decreased thymus weight, IL-2 production, circulating neutrophils, and superoxide anion production by macrophages (Percival, 1998). Copper oxide wire particles (COWP) added to sheep diets ameliorates $H$. contortus infection by decreasing FEC and the percentage of females in the abomasum (Burke et al., 2004). Different areas of the U.S vary in environmental copper levels limiting the use of COWP, as sheep are extremely sensitive to copper and high dietary levels may result in copper toxicity.

Prebiotics and probiotics are common dietary supplements that are known to enhance immune responses (Fuller, 1991). Prebiotics are not directly digestible by the body, but rather are consumed by GI bacteria. Many oligosaccharides function as prebiotics and examples include lactulose, lactose, fructose, galactose, and paltinose (Manning and Gibson, 2004). Prebiotics stimulate microflora growth and activity leading to maintenance of host health. Bifidobacteria, lactobacilli, propionibacteria, and enterococci are normal gut inhabitants (Gibson et al., 1995). These types of bacteria provide protection against harmful bacteria by blocking receptors or ligands present on gastrointestinal tract epithelium. Lactobacillus casei and L. rhaminosus are able to competitively exclude a variety of Escherichia and Salmonella species from binding to GI adhesion sites (Lee et al., 2003). Probiotics also limit the amount of detrimental bacteria by competing for nutrients. Clostridium difficile was outcompeted by normal mouse microflora for carbon sources in colon simulated cultures (Wilson and Perini, 1988). Stimulation of host defense mechanisms is the most important aspect of probiotic activity. Oral administration of $L$. casei increased the number of IgA secreting B cells, IL-6 producing cells, and alternatively activated macrophages (CD206 $\left.{ }^{+}\right)$in the 
lamina propria of the small intestines (Galdeano and Perdigón, 2006). Prebiotic supplementation increases probiotic propagation leading to an upregulation of protective immune responses.

\section{Immunosaccharides}

\section{$\beta$-glucans}

Beta glucans are glucose polymers that are found primarily in fungi and yeast cell walls. Soluble $\beta$-glucans have antitumor activity and prevent some experimental infectious diseases (Tzianabos, 2000). They non-specifically increase antimicrobial activity of lymphocytes and neutrophils, and enhance functional activities of macrophages. Human white blood cells incubated with increasing concentrations of $\beta$ glucans and then exposed to formyl-norleucyl-leucyl-phenylalanine (fNLP), which is a known neutrophil activator, showed significant dose dependent release of reactive oxygen species (Wakshull et al., 1999). Rats that received intramuscular injections of $\beta$-glucans and then were challenged with antibiotic resistant Staphylococcus aureus exhibited higher circulating monocytes (77\%) and neutrophils (38\%) 48 hours post challenge than mice who received saline (Liang et al., 1998). $\beta$-glucan signaling through dectin-1 receptors results in reprogramming of circulating monocytes. Researchers found upregulation of $\mathrm{H}_{3} \mathrm{~K}_{4} \mathrm{me}_{3}$ (involved with actively transcribed promoters) of innate immune genes and upregulated mRNA for TNF- $\alpha, I L-6, M R C-1$, and CD163 in mice monocytes primed with $\beta$-glucans (Quintin et al., 2012). This type of priming leads to macrophages with the potential to exhibit either a M1 or M2 phenotype. Immunomodulation of this type is ideal, as defenses are ready for any type of pathogen attack, including parasitic infections. 


\section{Zymosan}

Zymosan is a polysaccharide found in yeast cell walls. They are readily bound by dectin-1 receptors and TLR-2 found on DC, resulting in immunosuppressive activity. Murine DC cultured with zymosan for 24 hours produced high levels of IL-10 (Dillon et al., 2006; Goodridge et al., 2007). Complement is needed during innate immune responses and zymosan can act as a reservoir for C3b by accumulating C3b on its surface away from regulatory proteins. Trace-labeled C3 bound to the surface of zymosan was $65 \%$ resistant to inactivation by C3b inactivator accelerator (C3bINA) and beta $1 \mathrm{H}$ globulin compared to $95 \%$ loss of function that occurred to $\mathrm{C} 3 \mathrm{~b}$ bound on sheep erythrocytes (Fearon and Austen, 1977).

Zymosan is also able to induce inflammatory environments within the host. Murine lung tissue 2 days post zymosan injection developed severe alveolar wall thickening, hemorrhaging, and neutrophil infiltration (Jia et al., 2013). Rats intraperitoneally injected with zymosan exhibited dose dependent inflammatory cell infiltration into parietal peritoneum and increased fibrinogen accumulation even at day 36 post treatment (Mizuno et al., 2009). There is no report of immunomodulatory effects of zymosan during parasitic infections.

\section{Celmanax ${ }^{\circledR}$}

Celmanax® is a combination of mannan oligosaccharides (MOS), $\beta$-glucans, and yeast culture, produced by Saccharomyces cerevisiae. This commercially available prebiotic has demonstrated an immunomodulatory effect in several species of livestock. Supplementation of dairy cattle resolved pathology of jejunal hemorrhagic syndrome caused by consumption of moldy feed and decreased colonization of E. coli $\mathrm{O} 157: \mathrm{H} 7$ of 
bovine colon cells (Baines et al., 2011), and reduced somatic cell counts in milk (Nocek et al., 2011). Poultry studies have indicated that Celmanax® supplementation increases production values in transport/E. coli stressed turkeys (Huff et al., 2013), and reduction of Eimeria tenella oocyst shedding in broiler chickens resulting in decreased mortality rate (Hanan et al., 2012). Lactating sows had increased IgG levels in colostrum which lead to increased circulating IgG levels in piglets (Czech, 2010). Pigs fed MOS post weaning experienced slight increases in serum IL-10 and ex-vivo stimulation of alveolar macrophages with LPS resulted in reduced TNF- $\alpha$ production and more IL-10 secretion (Che et al., 2012). Effects of MOS supplementation to cattle, poultry, and swine indicate benefits to both innate and acquired immunity.

Several studies have been conducted on the immune-stimulatory effects of MOS and $\beta$-glucans in many livestock species; but few studies have examined the effects in sheep. Addition of dried S. cerevisiae to the diets of suckling lambs stimulated humoral and cellular immunity (Malaczewska and Milewski, 2010). However, with this study, evaluation of cellular immunity included metabolic activity and potential killing activity of phagocytes, and proliferation assays. Humoral immunity parameters assessed were lysozyme and ceruloplasmin activity, and gammaglobulin levels. There is little to no research conducted that has evaluated the effects of dietary immunomodulation and its role in aiding host clearance of helminth parasite infections. Therefore the objective of this study was todetermine the effect of Celmanax ${ }^{\circledR}$ on immune function during primary and challenge $H$. contortus infectionsof commercial crossbred sheep. 


\section{Chapter 2: In Vitro Experimentation}

\section{Materials and Methods}

Sheep and experimental design

Two St. Croix sheep and two Suffolk crossbred sheep from the WVU Animal Sciences Farm were used as a source for blood samples. Challenged sheep were produced by oral inoculation with 10,000 L3 stage Haemonchus contortus larvae, the infection was maintained for 7 weeks. Sheep were treated with the anthelmintic Levamisole hydrochloride (Simpson Pharmacy, Broken Bow, OK) and rested for 4 weeks, then re-administered $10,000 \mathrm{~L}_{3}$ stage larvae orally.

\section{Blood collection}

Blood was collected, via jugular venipuncture, into $10 \mathrm{~mL}$ EDTA-treated vacutainer tubes. Peripheral blood mononuclear cells were separated from whole blood samples first by collecting the buffy coat, then cells were resuspended using D-PBS [1x] (Cellgro, Manassas, VA). White blood cells were layered on LSM (MP Bio, Solon, OH), centrifuged at $400 \mathrm{Xg}$ for 20 minutes, and the PBMCs were collected and resuspended with complete media (RPMI (Hyclone 1640 medium, Logan, UT) + 5\% FBS (Biowest, Kansas City, MO) + Pen/Strep Combo (MPBio, Solon, OH)).

Monocyte isolation and in vitro culture conditions

Monocytes expressing $\mathrm{CD} 14^{+}$were targeted using a positive selection cocktail (StemCell Technologies, Vancouver, Canada) containing mouse anti-bovine CD14 ${ }^{+}$ antibody (AbDSerotec, Kidlington, Oxford). After the addition of nanoparticles (StemCell Technologies, Vancouver, Canada), PBMC were placed into an EasySep 
Magnet (StemCell Technologies, Vancouver, Canada) and CD14- cells were poured into a separation vial. Separated monocytes and lymphocytes were resuspended with DPBS. The number of monocytes was determined by staining an aliquot of the separated cells with trypan blue (MPBio, Solon, $\mathrm{OH}$ ). Stained cells were placed onto a Neubauer Hemaocytometer and viewed with a light microscope at $400 \mathrm{X}$ magnification. Macrophages were generated using complete media, complete media $+20 \mu \mathrm{g} / \mathrm{mL}$ Celmanax® (Vi-Cor, Mason City, IA), or complete media $+210 \mu \mathrm{L} H$. contortus antigen. Cells were incubated for 48 hours at $37^{\circ} \mathrm{C}$ and $5 \% \mathrm{CO}_{2}$.

PCR analysis

Cells were homogenized with RNA-Bee ${ }^{\mathrm{TM}}$ (Tel-Test, Friendswood, TX) and stored at $-80^{\circ} \mathrm{C}$. Supernatant was stored at $-80^{\circ} \mathrm{C}$ and RNA was isolated from macrophages using a chloroform/isoamyl alcohol extraction protocol. Total RNA was quantified using the Nano-Drop spectrophometry system and an absorbance ratio (A260:280) of greater than 1.8 was observed in RNA samples. RNA was reverse transcribed using SuperScript ${ }^{\circledR}$ III reverse transcriptase (Life Technologies, Carlsbad, CA) and cDNA concentration was measured using a Nano-Drop spectrophotometer. Samples were diluted to $4 \mathrm{ng} / \mu \mathrm{L}$ in RNase-free DEPC water and stored at $-20^{\circ} \mathrm{C}$. Primer sequences were designed using Primer3 software.

Real-time PCR reactions were conducted in a total volume of $25 \mu \mathrm{L}$, using $2.5 \mu \mathrm{L}$ of sample cDNA, $0.05 \mu \mathrm{M}$ of both forward and reverse primers, $7 \mu \mathrm{L}$ DEPC water, and 12.5 $\mu$ L SYBR Select Master Mix (Life Technologies, Burlington, ONT Canada). Amplification of cDNA fragments were detected by a BioRad CFX96 Touch $^{\mathrm{TM}}$ Real- 
Time PCR Detection System. Gene expression of the treated samples was determined by the fold change compared to control samples.

\section{Arginase and Nitric Oxide Assays}

Arginase activity was measured from supernatant collected from monocyte cultures after 48 hours of incubation using a Quantichrom ${ }^{\mathrm{TM}}$ Arginase Assay Kit (BioAssay Systems, Hayward, CA). Arginase activity was calculated using the assay kit's provided equation. Nitric oxide production was quantified using a Griess Reagent Assay Kit (Promega, Madison, WI). Concentrations of nitric oxide from the supernatant collected after 48 hours was compared to the standard curve produced from the assay. 


\section{Chapter 2: Results}

\section{Arginase Assays}

Naïve wool and hair control monocytes produced higher amounts of Arginase compared to naïve wool and hair monocytes cultured with Celmanax® (Figure 3). Challenge infected wool monocytes had relatively similar Arginase production when cultured with either Celmanax® or $H$. contortus antigen, these monocytes produced lower amounts compared to control monocytes. Challenged hair monocytes cultured with $H$. contortus antigen produced more Arginase than monocytes cultured with Celmanax® and controls. Control and Celmanax® cultured monocytes had similar production levels of Arginase.

\section{Nitric Oxide Assays}

Monocytes from a naïve wool sheep produced less nitric oxide when cultured with Celmanax® compared to control monocytes. Challenge infected wool monocytes produced less nitric oxide when cultured with Celmanax $®$ and even more so when cultured with $H$. contortus antigen. Naïve hair monocytes produced less nitric oxide when cultured with Celmanax® compared to controls. Challenge infected hair monocytes produced less nitric oxide when cultured with $H$. contortus antigen and even more so when cultured with Celmanax® (Figure 2).

\section{PCR analysis}

Genes such as Arg-1, CD206, iNOS, IGF-1, MMP-13, and TNF- $\alpha$ were upregulated in naïve wool monocytes cultured with Celmanax® compared to challenged wool monocytes cultured with Celmanax ${ }^{\circledR}$ or $H$. contortus antigen. Challenged wool 
monocytes cultured with Celmanax® expressed more COX-2, IL-10, and $I L-13$ compared to other wool monocyte groups. Challenged wool monocytes cultured with $H$. contortus antigen expressed more $I L-4$ and $I L-12$ compared with the other wool monocyte groups, in which no amplification was detected. IFN- $y$ and $I L-17$ were also tested, but no groups expressed detectable levels (Table 1).

Hair monocytes produced different trends. Naïve hair monocytes cultured with Celmanax $®$ expressed lower levels of $I G F-1$, and TGF- $\beta$ compared to both challenged hair monocyte groups, but they expressed higher IL-12 than the other two groups. They did not express IL-4 nor COX-2; however, they were the only group to express MMP-13. Challenged hair monocytes cultured with $H$. contortus antigen expressed higher levels of CD206, IGF-1, iNOS, IL-10, IL-13, TGF- $\beta$, and TNF- $\alpha$ than naïve and challenged hair monocytes cultured with Celmanax®. Challenged hair monocytes cultured with Celmanax ${ }^{\circledR}$ had no detectable expression of $C D 206$, iNOS, IL-10, IL-12, IL-13, or TNFa. $I L-4$ and COX-2 were expressed only by this group. Arg-1, YM-1 and IL-17 were also tested, but no groups expressed detectable levels (Table 2). 


\section{Chapter 3: In Vivo Experimentation}

\section{Materials and Methods}

\section{Experimental animals and design}

Thirty-nine parasite-naïve Dorset-Texel crossbred lambs were born in the fall of 2012 and raised on an elevated floor barn at the WVU Animal Sciences Farm. During the experiment, lambs were limit-fed $2 \mathrm{lbs} / \mathrm{hd}$ of a $16 \%$ CP corn-soybean grain twice a day including Celmanax ${ }^{\circledR}($ Vicor, Mason City, IA) $(1 \mathrm{~g} / \mathrm{hd} /$ day) $(\mathrm{n}=20)$ or without $(\mathrm{n}=19)$. After feeding Celmanax ${ }^{\circledR}$ for one week, 15 lambs in each group were infected with 10,000 L ${ }_{3}$ Haemonchus contortus larvae and the infection was allowed to persist for 49 days leaving five and four uninfected control lambs in each group respectively.

During the primary infection, ten lambs from the Celmanax® fed group, 7 infected and 3 naïve; and 10 lambs from the non-Celmanax fed group, 8 infected and 2 naïve (see figure 1); were euthanized via captive-bolt gun and exsanguination at the Virginia Tech Meats lab in Blacksburg, VA. Challenged sheep were generated by administering 10,000 $L_{3}$ stage $H$. contortus larvae orally, deworming with Levamisole Hydrochloride (Simpson Pharmacy, Broken Bow, OK) after 7 weeks, resting for 4 weeks, then readministering $10,000 \mathrm{~L}_{3}$ stage larvae orally to the remaining lambs. Blood samples were taken every $2 \mathrm{~d}$ for $14 \mathrm{~d}$, then weekly until $49 \mathrm{~d}$ after infection. Body weights were measured every two weeks during the primary infection.

\section{Blood collection}

Blood was collected, via jugular venipuncture, into a $10 \mathrm{~mL}$ vacutainer tube for serum analysis. Blood samples were allowed to clot and then centrifuged at $400 \mathrm{Xg}$ for 20 minutes at $4^{\circ} \mathrm{C}$. Serum was aliquoted into $1.5 \mathrm{~mL}$ centrifuge tubes. For packed cell 
volume (PCV) and blood cell analysis, additional blood samples were collected into $4 \mathrm{~mL}$ EDTA-treated vacutainer tubes. Total white blood cell counts were determined using a Beckman Coulter Z1 Cell Counter by mixing 10mL Isoton II diluent (Beckman Coulter, Pasadena, CA) with $20 \mu \mathrm{L}$ whole blood, and three drops of zap-o-globulin (Beckman Coulter, Pasadena, CA) lysing agent. White blood cell differentials were visually analyzed by Wright staining of blood smears.

\section{Parasitological analysis}

Fecal samples were taken weekly for 49 days post infection. Fecal eggs counts were determined from fecal samples using the McMaster's method (McMaster, 1948). Worm counts and larval development was assessed from 10\% abomasal aliquots. Counts were multiplied by a factor of 10 to get total worm burden.

\section{Abomasal and lymph node tissue collection}

Abomasum was removed and all palpable lymph nodes were extracted from the lesser curvature; associated fat was removed. Lymph nodes were counted, weighed and a $4 \mathrm{~mm}$ slice of the largest lymph node was preserved in $10 \%$ buffer formalin for histological analysis and RNA-later (Life Technologies, Carlsbad, CA) for RNA extraction. Abomasum was cut along the greater curvature and contents prepared as $10 \%$ aliquots and stored in $10 \%$ buffered formalin. The abomasum was washed with tap water and cut in half. One half was placed on ice and mucus, fundic and pyloric region mucosa and tissue were collected. Abomasal mucosa and tissue were placed in $10 \%$ buffered formalin histological analysis and RNA-later for RNA extraction. The other abomasum half was soaked in 1X PBS (CellGro, Manassas, VA) overnight at 
room temperature, then removed and remaining liquid was mixed with $10 \%$ buffered formalin to collect adult worms.

$\underline{P C R \text { analysis }}$

Total RNA was isolated from tissue samples using a chloroform/isoamyl alcohol extraction protocol. Total RNA was quantified using the Nano-Drop spectrophotometry system and an absorbance ratio (A260:280) of greater than 1.8 was observed in RNA samples. Total RNA was reverse transcribed into cDNA using SuperScript ${ }^{\circledR}$ III Reverse Transcriptase (Life Technologies, Carlsbad, CA) and cDNA concentration was measured using a Nano-Drop spectrophotometer. Lymph node cDNA samples were diluted to $10 \mathrm{ng} / \mu \mathrm{L}$ and mucosa cDNA was diluted to $15 \mathrm{ng} / \mu \mathrm{L}$ in RNase-free DEPC water (Fisher Scientific, Fair Lawn, NJ) and stored at $-20^{\circ} \mathrm{C}$. Primer sequences were designed using Primer3 software.

Real-time PCR reactions were conducted in a total volume of $20 \mu \mathrm{L}$, using $2 \mu \mathrm{L}$ of sample cDNA, $5 \mu \mathrm{M}$ of both forward and reverse primers, $5.6 \mu \mathrm{L}$ DEPC water, and $10 \mu \mathrm{L}$ SYBR® Green PCR Master Mix (Life Technologies, Carlsbad, CA). Amplification of cDNA fragments were detected by a BioRad CFX96 Touch $^{\text {TM }}$ Real-Time PCR Detection System. Fold change in gene expression was calculated using the $2^{-\Delta \Delta C t}$ method (Livak and Schmittgen, 2001). The obtained Ct values are used to calculate $\Delta \mathrm{Ct}$ values on genes of interest [Ct (test) - Ct (HKG)], whereas GADPH was used as the housekeeping gene in all analyses. The $\Delta \Delta \mathrm{Ct}$ values were obtained by referencing experimental $\Delta \mathrm{Ct}$ values to that of the naïve group. 


\section{$\underline{\text { Total Mucus and Serum IgA ELISA }}$}

To determine concentrations of capture and detection antibodies, checker board titrations were performed using a pooled sample of infected lamb serum from day 49 . Polyclonal anti-sheep IgA (AbD Serotec, Kidlington, Oxford) was diluted to $4 \mu \mathrm{g} / \mathrm{mL}$ in $0.05 \mathrm{M}$ carbonate-bicarbonate buffer $(9.6 \mathrm{pH})$ and placed in each well of a 96 -well $4 \mathrm{HBX}$ plate (ThermoScientific, Rochester, NY) and incubated overnight at $4^{\circ} \mathrm{C}$. Plates were then washed 3 times in PBS with $0.05 \%$ Tween-20 (PBS-T) and blotted dry. Plates were blocked with $200 \mu \mathrm{L}$ of PBS with $0.1 \%$ BSA (PBS-B) and allowed to incubate for 30 minutes at room temperature (RT) and washed again for 5 times. Diluted serum samples $(1: 10,000)$ and mucus samples (1:1000) in PBS-B were added in duplicate, then incubated for $2 \mathrm{hrs}$ at RT and washed 5 times. Polyclonal anti-sheep IgA conjugated with horseradish peroxidase (HRP) (AbD Serotec, Kidlington, Oxford) was diluted (1:10,000 for serum) and (1:4000 for mucus) and 100 $\mu \mathrm{L}$ were added to each well on the plate and incubated for 1 hour at RT. Plates were washed 10 times, then $100 \mu \mathrm{L}$ of TMB substrate (ThermoScientific, Rockford, IL) was added to each well and a colorimetric response was allowed to develop for 15 minutes and reaction was stopped using $100 \mu \mathrm{L}$ of $2 \mathrm{M} \mathrm{H}_{2} \mathrm{SO}_{4}$. Plates were read at a wavelength of $450 \mathrm{~nm}$ on a Bio-Tek ELx-800 microplate spectrophotometer. Total IgA values were compared to a sheep IgA standard curve with a maximum value of $1000 \mathrm{ng} / \mathrm{mL}$ and a minimum value of 15.6ng/mL. Inter-sample CV was less than $10 \%$ for all samples, however, if intersample CV exceeded $10 \%$ samples were analyzed again to reach an acceptable CV. Inter-plate CV was determined using absorbance of negative control samples and did not exceed $10 \%$. Values are reported as $\mathrm{mg} / \mathrm{mL}$. 


\section{$\underline{\text { Total and antigen specific serum IgG ELISA }}$}

Polyclonal anti-sheep IgG (Sigma-Aldrich, St. Louis, MO) diluted to $5 \mu \mathrm{g} / \mathrm{mL}$ in $0.05 \mathrm{M}$ carbonate-bicarbonate buffer $(9.6 \mathrm{pH})$ was placed in each well of a 96-well 4HBX plate (ThermoScientific, Rochester, NY) and incubated overnight at $4^{\circ} \mathrm{C}$. Plates were then washed 5 times in PBS-T. Plates were blocked with $200 \mu \mathrm{L}$ of PBS-B and allowed to incubate for $30 \mathrm{~min}$ at room temperature (RT) and washed again for 5 times. Diluted serum samples (1:7200 for total lgG) in PBS-B was added in duplicate, then incubated for 2 hrs at RT. Polyclonal anti-sheep IgG conjugated with HRP (Sigma-Aldrich, St Louis, MO) was diluted (1:10,000 for total $\lg G)$ and $100 \mu \mathrm{L}$ was added to each well on the plate and incubated for $1 \mathrm{hr}$ at RT. Plate was washed 10 times, then $100 \mu \mathrm{L}$ of TMB substrate (ThermoScientific, Rockford, IL) was added to each well and a colorimetric response was allowed to develop for 15 minutes and reaction was stopped using $100 \mu \mathrm{L}$ of $2 \mathrm{M} \mathrm{H}_{2} \mathrm{SO}_{4}$. Plate was read at a wavelength of $450 \mathrm{~nm}$ on a Bio-Tek ELx-800 microplate spectrophotometer. Total IgG values were compared to a sheep IgG standard curve with a maximum value of $1000 \mathrm{ng} / \mathrm{mL}$ and a minimum value of 15.6ng $/ \mathrm{mL}$. Inter-sample CV was less than $10 \%$ for all samples, however, if intersample CV exceeded $10 \%$ samples were analyzed again to reach an acceptable CV. Inter-plate CV was determined using absorbance of negative control samples and did not exceed $10 \%$. Values are reported as $\mathrm{mg} / \mathrm{mL}$.

\section{$\underline{\text { Antigen specific serum IgG ELISA }}$}

Crude worm antigen from $H$. contortus was diluted to $4 \mu \mathrm{g} / \mathrm{ml}$ in $0.05 \mathrm{M}$ carbonatebicarbonate buffer $(9.6 \mathrm{pH})$ and added to a 96 well $4 \mathrm{HBX}$ plate (ThermoScientific, Rochester, NY). Plates were allowed to incubate overnight at $4^{\circ} \mathrm{C}$ before washing 5 
times with PBS-T. Plates were blocked using $200 \mu$ of PBS-B per well. Plates were incubated at RT for 30 min then washed 5 times with PBS-T. Serum samples were diluted 1:600 in PBS-B and added to the plate in duplicate in addition to blanks and negative control. Plates were incubated at RT for 2 hrs followed by washing 5 times with PBS-T. Polyclonal anti-sheep IgG conjugated with (HRP), was diluted to 1:1500 and $100 \mu$ were added to all wells and plate was incubated at RT for $1 \mathrm{hr}$. Plates were washed 10 times with PBS-T, then $100 \mu \mathrm{L}$ of TMB substrate (ThermoScientific, Rockford, IL) was added to each well and a colorimetric response was allowed to develop for 15 minutes and reaction was stopped using $100 \mu \mathrm{L}$ of $2 \mathrm{M} \mathrm{H}_{2} \mathrm{SO}_{4}$. Optical density was measured using a Bio-Tek ELx-800 microplate spectrophotometer at 450nm. All values were adjusted by subtracting the absorbance value of the blanks. Inter-sample CV was less than $10 \%$ for all samples, however, if inter-sample CV exceeded $10 \%$ samples were analyzed again to reach an acceptable CV. Inter-plate CV was determined using absorbance of negative control samples and did not exceed 10\%. Data reported are blank-adjusted optical density (OD) values at $450 \mathrm{~nm}$.

\section{Mannose-binding lectin C ELISA}

Mannose-binding lectin C assay (My BioSource, San Diego, CA) was conducted according to manufacturer's protocol. Serum was pooled within treatment groups and diluted 1:20. Reagents were allowed to come to RT, then $50 \mu \mathrm{L}$ of standards and samples were added to duplicate wells. Horseradish peroxidase-conjugated reagent was added to all wells at a volume of $100 \mu \mathrm{L}$ and incubated for $1 \mathrm{hr}$ at $37^{\circ} \mathrm{C}$, then washed 4 times. Chromogen solution was added to each well and incubated away from light for 15 minutes at $37^{\circ} \mathrm{C}$. Reaction was stopped by adding $50 \mu \mathrm{L}$ of stop solution to each 
well. Plates were read at a wavelength of $450 \mathrm{~nm}$ on a Bio-Tek spectrophotometer. Total MBL-C values were compared to a MBL-C standard curve with a maximum value of $1000 \mathrm{ng} / \mathrm{mL}$ and a minimum value of $15.6 \mathrm{ng} / \mathrm{mL}$.

\section{Histology Slide Prep}

Small, longitudinal slices of both the fundic and pyloric region of abomasal tissue were embedded in paraffin, cut and stained with hematoxylin and eosin $(\mathrm{H} \& \mathrm{E})$ by the Pathology Laboratory for Translational Medicine Histology at the West Virginia University Health Sciences Center. Eosinophils above and below the abomasal muscularis were visualized at 400X. Forty non-sequential views of each sample were counted using a grid reticule, and data are reported as the average count of cells $/ \mathrm{mm}^{2}$.

\section{Statistical Analysis}

Peripheral white blood cell counts and contrasts were analyzed as an

unbalanced, $2 \times 2$ factorial design using the repeated measures ANOVA procedure of SAS. Fixed effects included treatment, infection, day, all two way interactions, and three way interactions. Lamb number 3033 was excluded from the primary infection data sets, because it was a repeated outlier. Data from lamb 3036 was also removed from analysis on day 10 post challenge infection as it was an extreme outlier. Basophils were not analyzed, because they were not normally distributed and could not be transformed. Data were transformed as the natural logarithm of cell counts, except monocytes and eosinophils. Monocytes and eosinophils were transformed by using the natural logarithm of individual counts divided by the average count across all time points plus 0.3 before statistical analysis. Means were compared using t-tests and probability was calculated using the Tukey-Kramer adjustment for comparisons. 
Histological eosinophil counts were log transformed to better fit a Poisson distribution and an over-dispersion correction was used. Data were analyzed using a generalized linear model with fixed effects being treatment, infection, and their interaction. A selected Chi-square test was performed for the contrasts.

Lymph node counts were analyzed using a generalized linear model with a Poisson distribution. Lymph node weights were analyzed using a generalized linear model with fixed effects being treatment, infection, and their interaction. Lamb number 3027 was excluded as an outlier from primary lymph node count analysis.

Fecal egg counts (FEC) were transformed by $\log (\mathrm{FEC}+25)$ to create a normal distribution. Counts were analyzed using a mixed, repeated ANOVA and followed by a Tukey-Kramer adjustment for multiple comparisons. Worm burdens were transformed by $\ln ($ burden +.03$)$ then only infected animals were analyzed by a one way ANOVA.

Serum $\lg A$ were transformed by $\ln (\lg A)$ to create a normal distribution. Concentrations were analyzed using a mixed, repeated ANOVA and followed by a Tukey-Kramer adjustment for multiple comparisons. Mucus IgA was analyzed using a mixed ANOVA with a 2X2 factorial arrangement of treatments, followed by a TukeyKramer adjustment for multiple comparisons. Serum IgG concentrations were analyzed using a mixed, repeated ANOVA procedure, followed by Tukey-Kramer adjustment for multiple comparisons. Antigen specific lgG (CWA-lgG) was transformed by taking the In(CWA) analyzed using a mixed, repeated ANOVA with a $2 \times 2$ factorial arrangements of treatments. Serum MBL-C was transformed by taking the $\ln (M B L-C+2)$ then 
analyzed using a general linear model ANOVA with a 2X2 factorial design in time blocks, followed by Tukey-Kramer with adjustments for multiple comparisons.

Gene expression data were analyzed by using ANOVA in a 2X2 factorial design. Tests were conductedon $\Delta C T$ values. Gene expression for lymph node $I L-13$ during the primary infection was left skewed, and therefore was transformed using cube root before it was analyzed. 


\section{Chapter 3: Results}

\section{Parasitological measures}

Infected animals had significantly higher average FEC than uninfected animals (1147 eggs/g vs. 3 eggs/g; $P<.0001$ ) during the primary infection (Figure 4). During challenge infection, infection status also had a significant effect on FEC (320 eggs/g vs. 0 eggs/g; $P<.05)$ (Figure 4). There were no effects of treatment on worm burden during either primary or challenge infection.

\section{Peripheral White Blood Cell Counts}

During the primary infection, there was no significant difference in total white blood cells, monocytes, or lymphocytes. There were significant effects of treatment and day on eosinophil counts; Celmanax® treated lambs had greater circulating eosinophils $(655,245$ cells $/ \mathrm{ml})$ vs. untreated lambs $(451,357$ cells $/ \mathrm{ml})(P<0.05)($ Figure 7$)$. Averaged across all time points, infected lambs had higher circulating neutrophils $\left(8.6 \times 10^{6}\right.$ cells $/ \mathrm{ml})$ than uninfected lambs $\left(6.8 \times 10^{6} \mathrm{cells} / \mathrm{ml}\right)(P<0.05)($ Figure 6$)$. Treatment significantly increased PCV $(P<0.05)$ (Figure 5).

Analysis of challenge infection data indicated significant treatment effect and treatment by infection interaction for eosinophil counts. Celmanax® treated lambs $(5.11$ $X 10^{5}$ cells $\left./ \mathrm{ml}\right)$ had higher eosinophil counts than untreated lambs $\left(2.24 \times 10^{5} \mathrm{cells} / \mathrm{ml}\right)$ $(P<0.0001)$ (Figure 7). Treated, uninfected lambs had higher eosinophils than untreated, infected and control groups $(P<0.01)$. Additionally, treated, infected lambs had significantly higher eosinophils than untreated, infected lambs $(P<0.05)$. Infection had significant effects on lymphocytes and neutrophil. Infected groups had lower 
lymphocytes $\left(4.2 \times 10^{6} \mathrm{cells} / \mathrm{ml}\right.$ vs. $\left.5.6 \times 10^{6} \mathrm{cells} / \mathrm{ml}\right)$ and neutrophils $\left(2.4 \times 10^{6}\right.$ cells $/ \mathrm{ml}$ vs. $3.6 \times 10^{6}$ cells $\left./ \mathrm{ml}\right)$ than uninfected groups $(P<0.05$ and $<0.01$, respectively $)$ (Figure 6). There were no significant effects of treatment or infection on monocytes, PCV, or total white blood cells during challenge infection.

\section{Histological Eosinophil Counts}

Eosinophils counts of $\mathrm{H} \& \mathrm{E}$ stained abomasal fundic regions collected at day 49 post primary infection revealed a significant effect of infection on eosinophil counts with infected lambs on average having 13.2 times higher number of eosinophils than uninfected lambs $(P<0.05)$ (Figure 7$)$. There were no effects of treatment or infection on eosinophils in the pyloric region.

A significant effect was also seen for infection from the fundic region taken after the secondary infection. Infected lambs had 5.6 times higher eosinophils compared to uninfected lambs $(P<0.05)$ (Figure 6). There were no significant differences between untreated, infected lambs and untreated, uninfected lambs. No significant effects of treatment or infection on eosinophilia were observed in the pyloric region.

\section{Abomasal Lymph Nodes and Tissues}

Infection had a significant effect on lymph node weights during both the primary and challenge infection. Lymph nodes of primary infected lambs weighed two times more $(P<0.05)$ than uninfected lambs and lymph nodes of challenge infected lambs weighed three times more $(P<0.01)$ that uninfected lambs (Figure 10). No main effects of treatment or infection were observed in lymph node counts during the primary or challenge infection. 


\section{ELISA Data}

A significant treatment byinfection interaction was seen for serum IgA during the primary infection. Control animals had significantly higher serum $\lg A(2.69 \mathrm{mg} / \mathrm{mL})$ than non-treated, infected animals $(1.53 \mathrm{mg} / \mathrm{mL})(P<0.05)$ (Figure 9). There were no significant effects on mucus IgA during the primary infection or serum IgA during the challenge infection.

Infected animals had significantly higher circulating $\lg G(1.02 \mathrm{mg} / \mathrm{mL})$ compared to uninfected animals $(0.82 \mathrm{mg} / \mathrm{mL})(P<0.01)$ (Figure 12). No significant effects of treatment or infection were observed for CWA-IgG (Figure 10).

Serum MBL-C during the primary infection was significantly increased by treatment and infection $(P<0.0001)$. Treated groups had an average of $31.35 \mathrm{mg} / \mathrm{mL}$ vs. $5.66 \mathrm{mg} / \mathrm{mL}$ seen in non-treated groups. Infected sheep had $28.63 \mathrm{mg} / \mathrm{mL}$, whereas uninfected sheep had $8.38 \mathrm{mg} / \mathrm{mL}$. During secondary infection, treated groups had significantly higher MBL-C than non-treated groups $(27.76 \mathrm{mg} / \mathrm{mL}$ vs. $0.85 \mathrm{mg} / \mathrm{mL}$ ) $(P<0.0001)$. Infection also significantly increased MBL-C levels $(21.28 \mathrm{mg} / \mathrm{mL}$ vs. $7.33 \mathrm{mg} / \mathrm{mL})(P<0.05)$. There was also a significant treatment by infection interaction. Control sheep were significantly lower than all other groups $(P<0.05)$. Treated, infected sheep were significantly higher than untreated, uninfected sheep $(P<0.05)$ (Figure 11).

\section{Gene expression}

Many genes were significantly down regulated in lymph nodes as a result of infection. $I L-4 R$ during the primary infection $(P<0.05), I L-12$ during the challenge infection $(P<0.01)$, FOXP3 during the challenge infection $(P<0.05)$, IFN- $y$ during the 
challenge infection $(P<0.01)$ were all downregulated due to infection. Treatment also downregulated $I L-4 R$ during the primary infection $(P<0.05)$ (Table 3$)$.

Neither treatment nor infection had much of an effect on gene expression in the fundic mucosa. Infection significantly upregulated IL-12 during the primary infection $(P<0.05)$. During challenge infection, treatment significantly downregulated $T N F-\alpha$ $(P<0.01)$ (Table 4). Significant treatment by infection interactions were observed as treated, uninfected sheep had significantly lower TNF- $\alpha$ than both untreated groups $(P<0.05)$ (Figure 12). 


\section{Chapter 4: Discussion}

A key component of Celmanax $®$ is mannose, and important to note is that AAM express CD206 (mannose receptor-1) on their surface and have been implicated in development of full host protective immunity to helminth parasites. Separation of monocytes from whole blood and stimulation with Celmanax® in vitro allowed observation of direct effects on immune cells. When challenged hair monocytes were cultured with Celmanax $\circledast$ there were no detectable levels of any $\mathrm{TH}_{\mathrm{H}} 2$, regulatory, or wound repair genes; similar to hair sheep-derived naïve cells which showed no upregulation of these genes either. Although no response to Celmanax® was observed, monocytes exposed to parasite antigen generate expression of CD206 and IL-13. These cells also had high arginase activity, typically seen during helminth infections. Taken together these preliminary data indicate that hair sheep monocytes did not respond to immunomodulation, at least by Celmanax®. This could be contributed to the fact that hair sheep already have adequate immune responses and need no further stimulation. It should also be noted that many Celmanax® studies have been conducted in very clean facilities, such as dairy barns, where the animals have not any exposure to common pathogens. In those studies, no effect of Celmanax® was detected, but subsequent experiments in areas open for pathogen exposure Celmanax® exerted modulation of immune responses. Our sheep have been kept in facilities where their immune systems have worked through coccidiosis and pneumonia, providing optimum opportunities for pathogen challenge.

Wool sheep monocytes cultured with $H$. contortus antigen had relatively no change in gene expression compared to controls, further indicating lack of response in 
these sheep. When naïve monocytes were cultured with Celmanax® there was upregulation of CD206 and MMP-13. Similar results were seen when isolated human monocytes were primed for 24 hours with $\beta$-glucan, resulting data showed upregulation of CD163 and CD206, both markers of a M2 phenotype, but TLR-2 and-4 were also upregulated suggesting that an additional ligand maybe required to completely commit these cell to a M2 phenotype (Quintin et al., 2012). Intra-peritoneal injection of lentinan (a $\beta-1,3$ glucan) to mice infected with Mesocestoides corti increased the presence of liver granulomas containing dead or dying larvae surrounded by large numbers of macrophages along with more fibrosis (White et al., 1988). Challenged wool sheepderived monocytes cultured with Celmanax® expressed the most IL-10 and IL-13 of the three groups. Celmanax ${ }^{\circledR}$ seems to have beneficial effects on wool monocytes by polarizing them towards AAM phenotypes. These indicate that breed differences exist in relation to immunomodulation in at least macrophages.

Supplementation of Celmanax® to Dorset-Texel crossbred lambs resulted in immunological effects, specifically, eosinophils in the periphery. These cells were consistently higher in treated lambs during both primary and challenge infections. During the primary infection, Celmanax® treated lambs had significantly higher eosinophilsthan lambs that did not receive supplementation. Supplementation during a challenge infection produced the same effect. Significant treatment by infection interactions occurred during the challenge infection as well. Uninfected, treated lambs had a six-fold increase of eosinophils compared to controls and a three-fold increase of eosinophils compared to infected, untreated lambs. Celmanax $\AA$ treated, infected lambs had roughly 1.8 times higher circulating eosinophils than untreated, infected lambs. 
Eosinophils are a hallmark sign of helminth infection (Balic et al., 2000b). Increased eosinophil levels in treated lambs suggest Celmanax® is exerting an adjuvant effect. Administration of LPS and Propionibacterium acnes to sheep before experimental infection with $H$. contortus resulted in increased circulating eosinophils (Abel et al., 2009). Further separation of treatment groups during a second supplementation supports the possibility of memory being generated not only to $H$. contortus but also to Celmanax®. If an immune response is against Celmanax®, it is not a specific response. Histological sectioning of abomasal tissue from the fundic region showed no eosinophilia as a result of supplementation. Increased eosinophil presence was due to parasite infections. These results are consistent with previous reports. Lacroux et al. (2006) observed greater eosinophil infiltration of the abomasal mucosa in infected sheep compared to uninfected sheep. Enumeration of abomasal eosinophils during a primary $H$. contortus infection revealed three times higher eosinophils in infected lambs than uninfected lambs (Balic et al., 2000a).

Packed cell volume was significantly increased due to Celmanax® treatment during primary infection. Treated, uninfected animals had significantly higher PCV than all other groups. Calculation of change in PCV at day 0 post infection and day 49 post infection reveals that Celmanax® treated and uninfected lambs had the least amount of change with an increase of $0.2 \%$ whereas the others groups decreased from $1.6 \%$ (untreated, infected), 3.4\% (treated, infected), or $5.6 \%$ (control). It is possible that Celmanax ${ }^{\circledR}$ has a role in stabilizing PCV ultimately providing protection against bloodfeeding pathogens. However, the largest difference between two groups is $3.85 \%$, though statistically significant may not be biologically relevant as PCV of infected lambs 
remained in a normal range. Infection resulted in significantly higher circulating neutrophils during the primary infection, but then significantly lower neutrophils during the challenge infection. Decreased circulating neutrophils could be a result of increased migration to the site of infection. Neutrophil infiltration at the host-parasite interface has been reported in $H$. contortus infections (Bowdridge, 2009), precisely around days 35 and 42 post infection (Shakya et al., 2009).

Reduction of circulating lymphocytes as a result of a challenge infection could be a result of activated adaptive immune responses. Memory $T$ cells extravasate to sites of infection by chemokines produced by APCs at that site, possible explaining this phenomenon. Mice experimentally infected with $H$. polygyrus have specific localization of $\mathrm{CD}_{4}{ }^{+} \mathrm{T}$ cells around $\mathrm{L}_{3}$ stage larvae only during a challenge infection (Morimoto et al., 2004). Decreased IFN- $y, I L-12$ and FOXP3 mRNA expression within the lymph node during the challenge infection indicates that an active $\mathrm{TH} 2$ response is occurring in infected lambs. This is further supported by a decrease in TNF- $\alpha$ mRNA within the fundic mucosa during the challenge infection. Significant increases in lymph node weights due to infection were not unexpected. As early as five days post infection, doubling of abomasal lymph node weights occurs during a primary infection (Balic et al., 2000a). Lymph node hypertrophy is indicative of an active infection and caused by lymphocyte proliferation. Secondary exposure to a pathogen results not only in activation of memory T cells, but also B cells. This would explain the increased total serum IgG during the challenge helminth infection. Haemonchus challenged sheep had significantly systemic $\lg G$ (Lacroux et al., 2006). The reduction of serum IgA in untreated, infected lambs compared to the control lambs during the primary infection 
contradicts popular literature. Commonly, serum IgA increases as a result of infection even during a primary infection (Schallig, 2000). Serum IgA against adult E/S products was positively correlated $(r=0.649)$ with FEC (Bambou et al., 2008). Perhaps the fact that our lambs had reduced FEC lowered their requirement of IgA resulting in lower serum levels.

Mannose binding lectin- $\mathrm{C}$ is a soluble pattern-recognition molecule that activates serum protease, MASP-2, ultimately triggering the complement cascade of the lectin pathway (Tizard, 2013). Concentration of MBL-C was higher in Celmanax® treated groups compared to untreated groups and was expected considering a main ingredient is mannose. Increased presence of MBL-C in infected animals is a result of carbohydrates present on the parasite. It has been determined the three most prevalent carbohydrate epitopes on $H$. contortus are mannose, glucose, and $\mathrm{N}$-acetylglucosamine (Schallig et al., 1996); all of which are ligands of MBL-C. Increased MBL-C circulation within the host can lead to a rapid release of $\mathrm{C} 3$ resulting in fast opsonization, thus priming the host for accelerated clearance of pathogens.

Dorset sheep are generally considered parasite susceptible. When grazing infected pastures Dorset sheep shed significantly more $H$. contortus eggs and have a 99\% greater worm burden than parasite resistant sheep (Gamble et al., 1992a). Lack of treatment effects on FEC or worm burden may be attributed to the Texel influence. Texel sheep co-grazed with Suffolk sheep on naturally infected pastures in the temperate climate had lower FEC and worm burden each year during the three year study (Good et al., 2006). It has been reported that genetic resistance to GIN infections by Texel sheep is related to the presence of the IFN-ץ B haplotype (Sayers et al., 
2005b). Texel sheep have more diversity in their MHC-DRB1 alleles compared to Suffolk, which is correlated to their decreased FEC (Sayers et al., 2005a). Taken together it is fair to question the need for immunomodulation in this breed or its crosses, since they behave similar to parasite-resistant sheep.

This study provides evidence that there are immunomodulatory properties of Celmanax® based on its ability to increase circulating eosinophils and MBL-C within serum in lambs only supplemented. Upregulation of these immune markers point toward activation of innate immunity. Celmanax $®$ activity may prime macrophages to differentiate into M2 macrophages. Nevertheless, the efficacy of Celmanax® incorporation into lamb rations may be dependent upon the parasite-resistance status of the lambs being fed. 


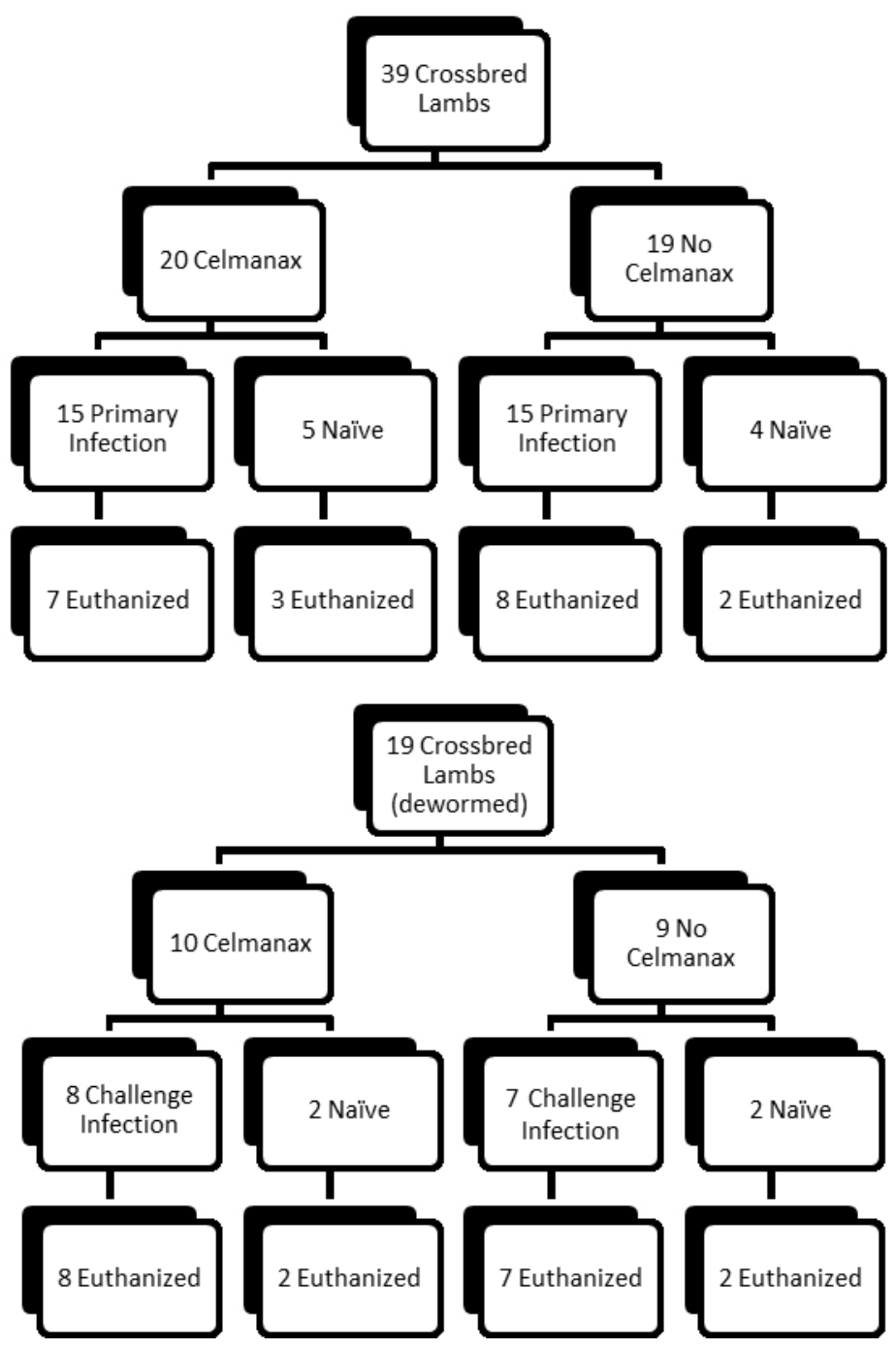

Figure 1. Experimental schematic.

A total of 39 lambs were used at the beginning of this experiment. Lambs not sacrificed at the end of the primary infection were dewormed and rested for 4 weeks before administering the secondary infection. 

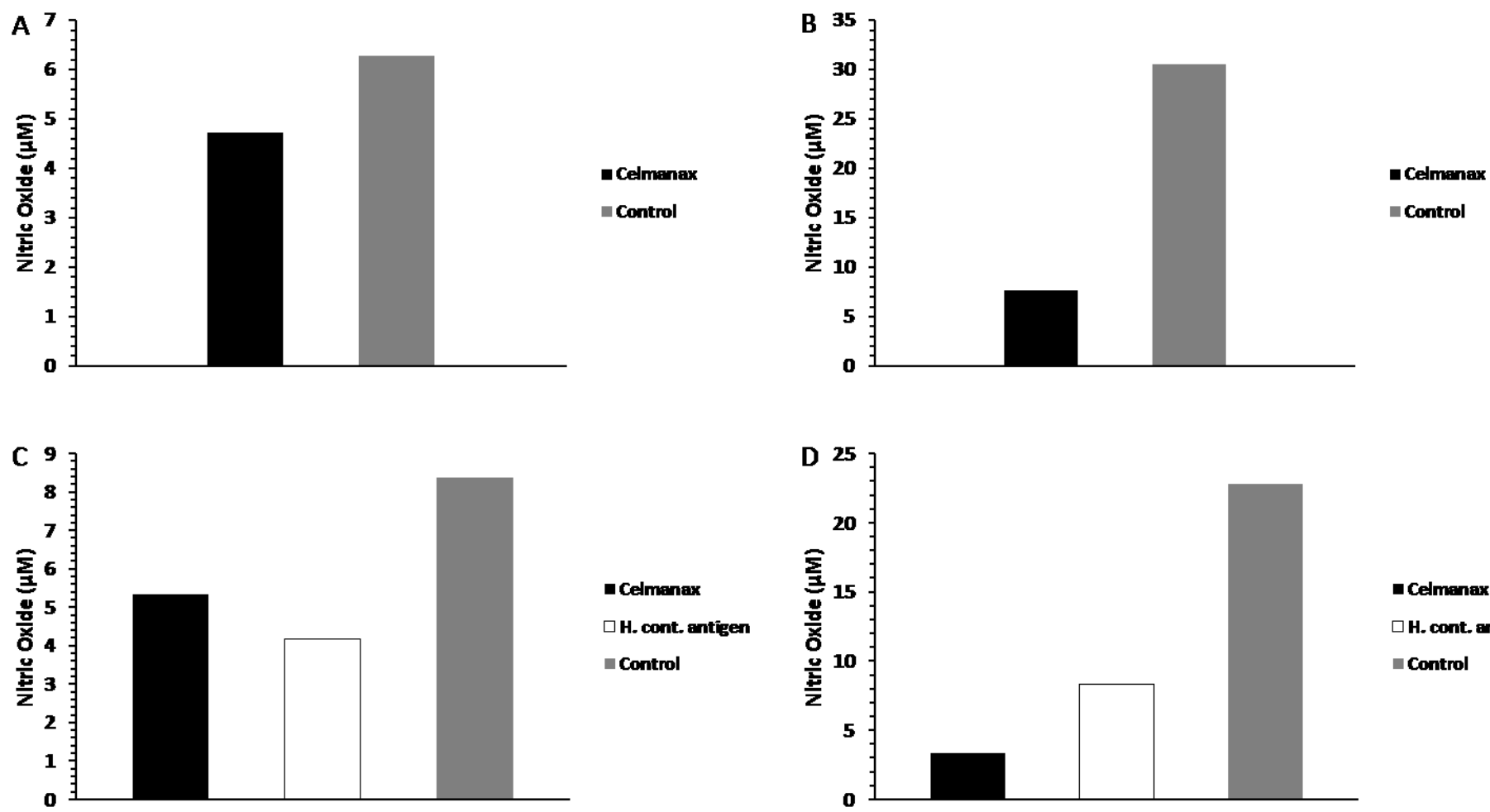

n Celmanax

$\square$ H. cont. antigen

n Control

Figure 2. Nitric Oxide production of stimulated monocytes invitro.

Monocytes extracted from whole blood of naïve wool sheep (A), naïve hair sheep (B), challenge wool sheep (C), and challenge hair sheep (D) were stimulated with $H$. contortus antigen or Celmanax $®$ and culture supernatant was analyzed for NO production. 

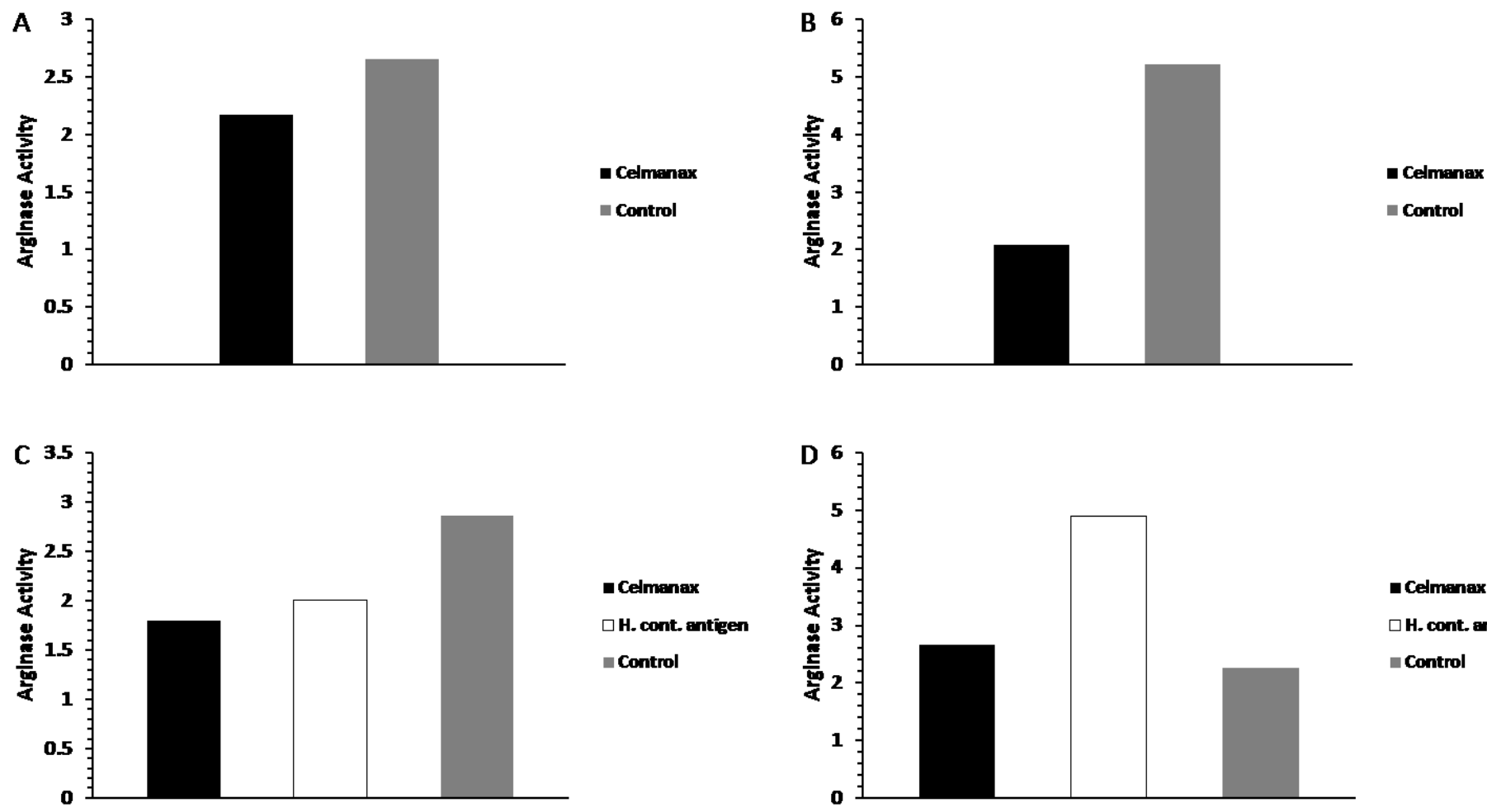

- Celmanax

$\square$ H. cont. antigen

nControl

Figure 3. Arginase activity of stimulated monocytes in vitro.

Monocytes extracted from whole blood of naïve wool sheep (A), naïve hair sheep (B), challenge wool sheep (C), and challenged hair sheep (D) were stimulated with $H$. contortus antigen or Celmanax $®$ and culture supernatant was analyzed for arginase activity. 


\begin{tabular}{|c|c|c|c|}
\hline Gene & $\frac{\text { Naïve Wool w/ }}{\text { Celmanax FC }}$ & $\begin{array}{l}\text { Challenged Wool } \\
\underline{w / C e l m a n a x ~ F C ~}\end{array}$ & $\frac{\text { Challenged Wool w/ }}{\text { H. cont. Ag FC }}$ \\
\hline ARG-1 & 个 & ND & $\downarrow$ \\
\hline CD28 & $\uparrow$ & $\uparrow$ & $\uparrow$ \\
\hline CD206 & $\uparrow$ & ND & $\downarrow$ \\
\hline $\operatorname{cox}-2$ & ND & - & - \\
\hline IGF-1 & $\uparrow$ & ND & ND \\
\hline iNOS & - & - & $\downarrow$ \\
\hline IL-4 & ND & ND & $\downarrow$ \\
\hline IL-10 & $\downarrow$ & $\uparrow$ & - \\
\hline IL-12 & ND & $\downarrow$ & $\downarrow$ \\
\hline IL-13 & ND & $\uparrow$ & $\downarrow$ \\
\hline MMP-13 & $\uparrow$ & $\downarrow$ & $\downarrow$ \\
\hline TGF- $\beta$ & $\downarrow$ & $\downarrow$ & - \\
\hline TNF- $a$ & $\downarrow$ & $\downarrow$ & $\downarrow$ \\
\hline YM-1 & ND & ND & - \\
\hline
\end{tabular}

Table 1.Wool monocyte gene expression during in vitro experiment. 


\begin{tabular}{|c|c|c|c|}
\hline Gene & $\frac{\text { Naïve Hair w/ }}{\text { Celmanax FC }}$ & $\frac{\text { Challenged Hair w/ }}{\text { Celmanax FC }}$ & $\frac{\text { Challenged Hair w/ }}{\text { H. cont. Ag FC }}$ \\
\hline ARG-1 & ND & ND & ND \\
\hline CD28 & $\downarrow$ & $\uparrow$ & $\uparrow$ \\
\hline CD206 & $\downarrow$ & ND & $\uparrow$ \\
\hline cox-2 & ND & ND & $\downarrow$ \\
\hline IGF-1 & 个 & $\uparrow$ & 个 \\
\hline iNOS & $\downarrow$ & ND & $\uparrow$ \\
\hline IL-4 & ND & ND & $\uparrow$ \\
\hline IL-10 & - & ND & - \\
\hline IL-12 & $\downarrow$ & ND & $\downarrow$ \\
\hline IL-13 & $\downarrow$ & ND & $\uparrow$ \\
\hline MMP-13 & $\downarrow$ & ND & ND \\
\hline TGF- $\beta$ & $\uparrow$ & $\uparrow$ & $\uparrow$ \\
\hline TNF- $\alpha$ & $\downarrow$ & ND & $\uparrow$ \\
\hline YM-1 & ND & ND & ND \\
\hline
\end{tabular}

Table 2. Hair monocyte gene expression during in vitro experiment. 

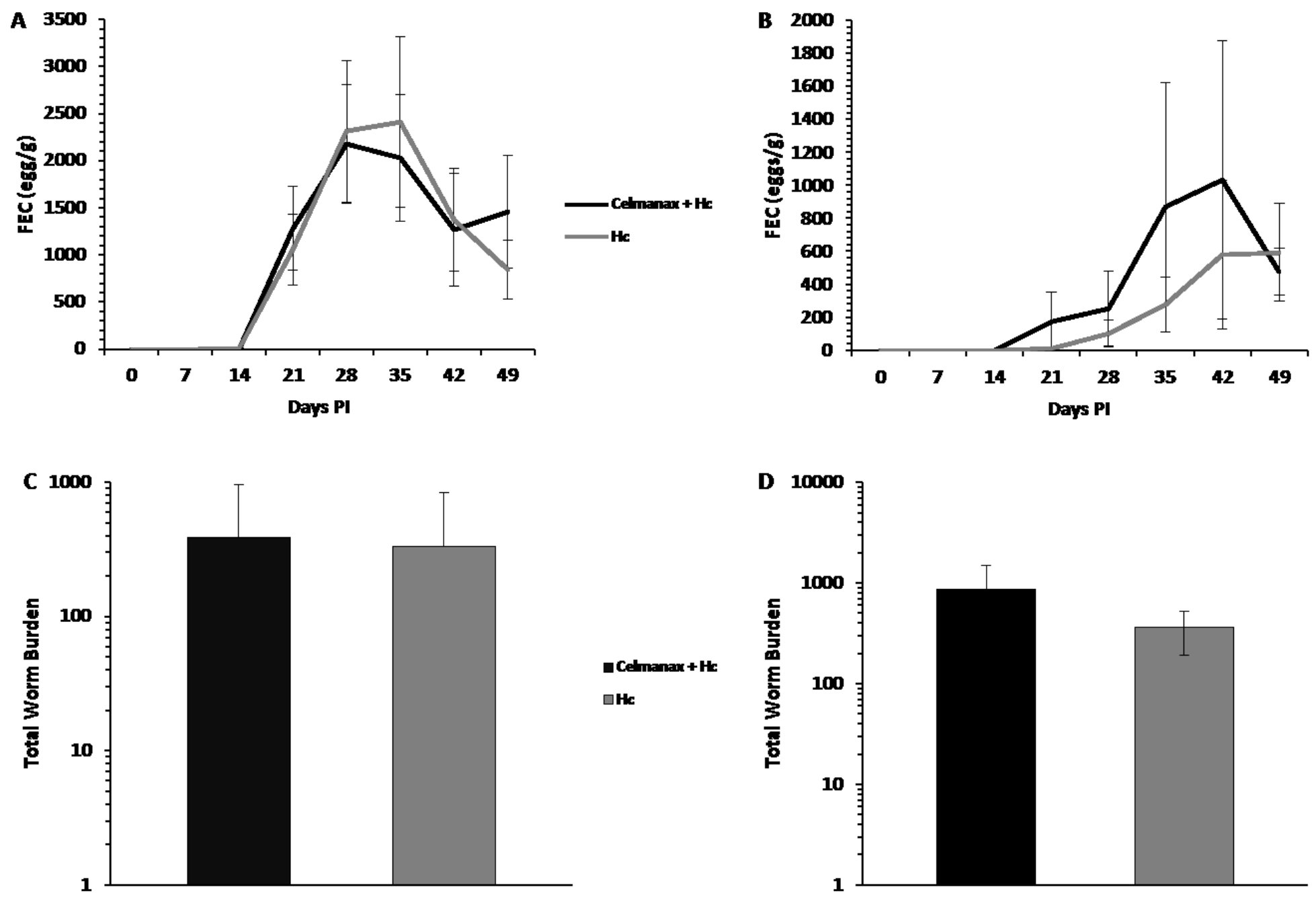

Figure 4. Fecal egg count and worm burden of lambs during primary and challenge $H$. contortus infections.

Dorset-Texel crossbred lambs were administered a $H$. contortus primary infection $(A)$ and a challenge infection (B) and FEC were taken weekly. Forty-nine days after infections lambs were harvested and abomasal worm counts were performed on lambs receiving a primary infection (C) and challenge infection (D). Error bars represent SEM. 

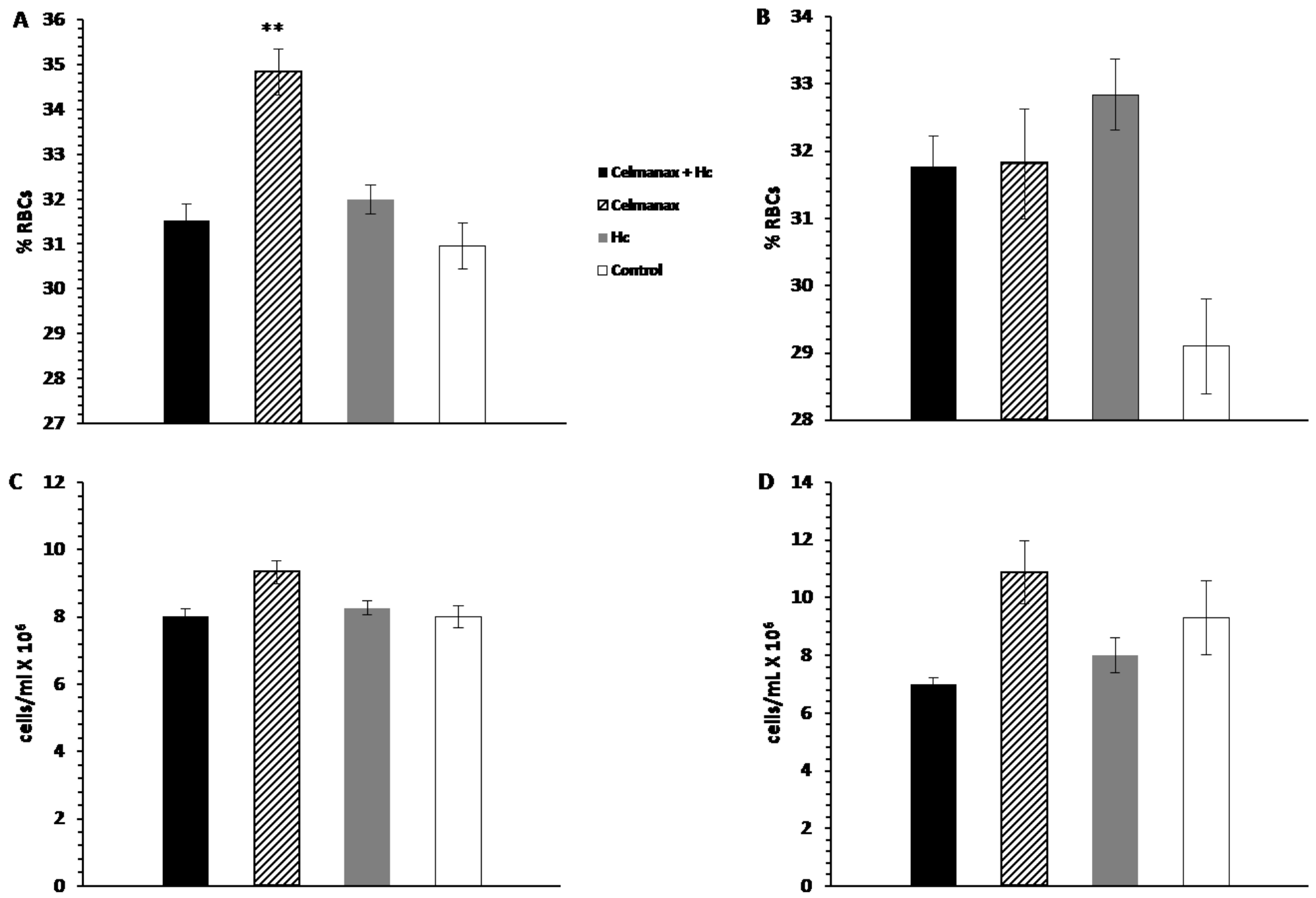

Figure 5. Packed cell volume and total WBC counts of lambs during $H$. contortus infections.

Average PCV across the duration of the experiment during primary infection $(A)$ and challenge infection (B). White blood cell counts were averaged across the experiment during the primary infection (C) and challenge infection (D). Error Bars represent SEM. ${ }^{* *} P<0.01$. 

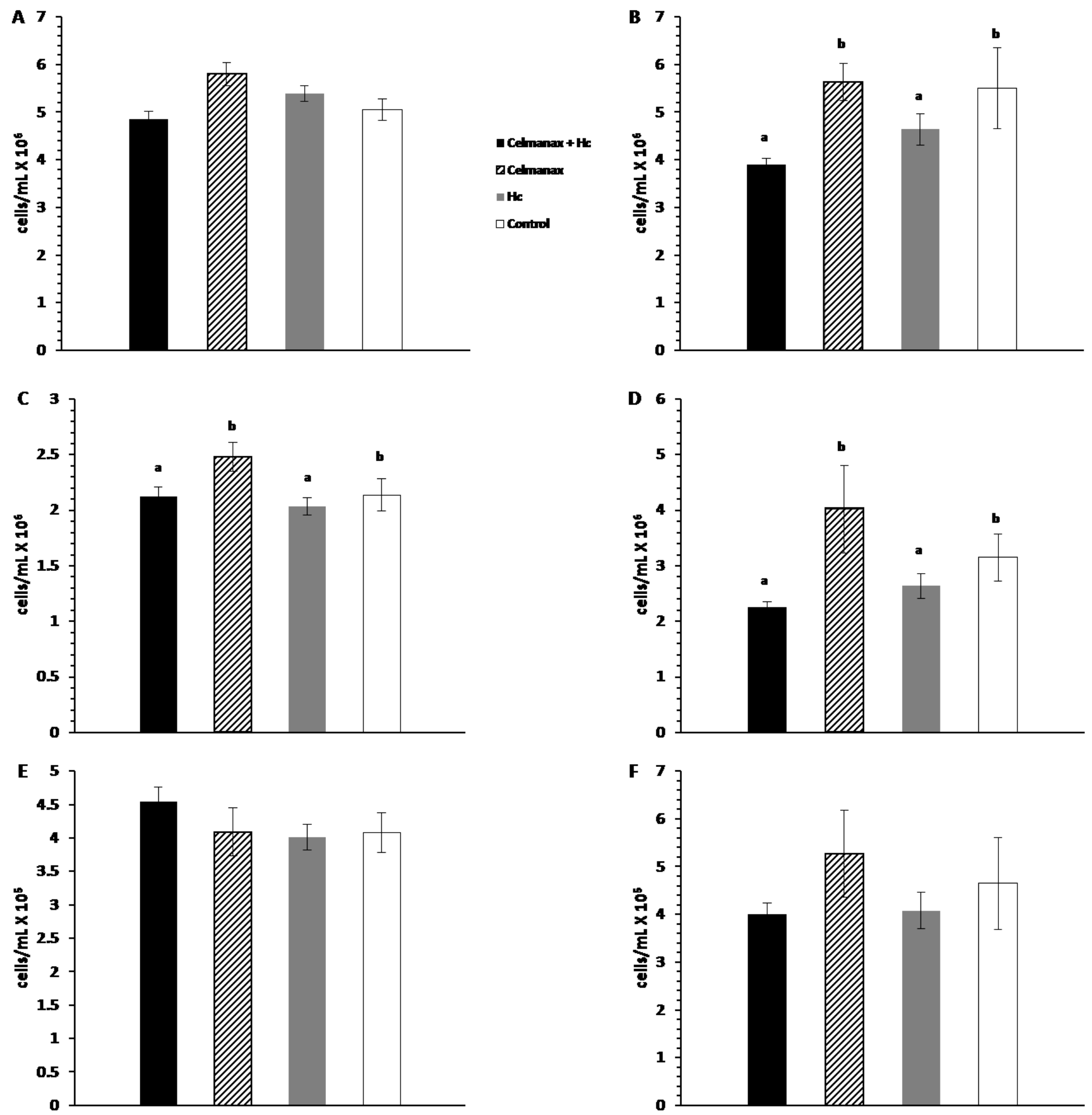

Figure 6. White blood cell differential counts during primary and challenge $H$. contortus infections.

White blood cell differential counts were performed at each time point and averaged to represent cell count of lymphocytes during primary infection $(A)$ and challenge infection $(B)$, neutrophils during primary infection (C) and challenge infection (D), and monocytes during primary infection (E) and challenge infection (F). Error bars represent SEM. Means not connected by the same letter are significantly different at $<0.05$. 

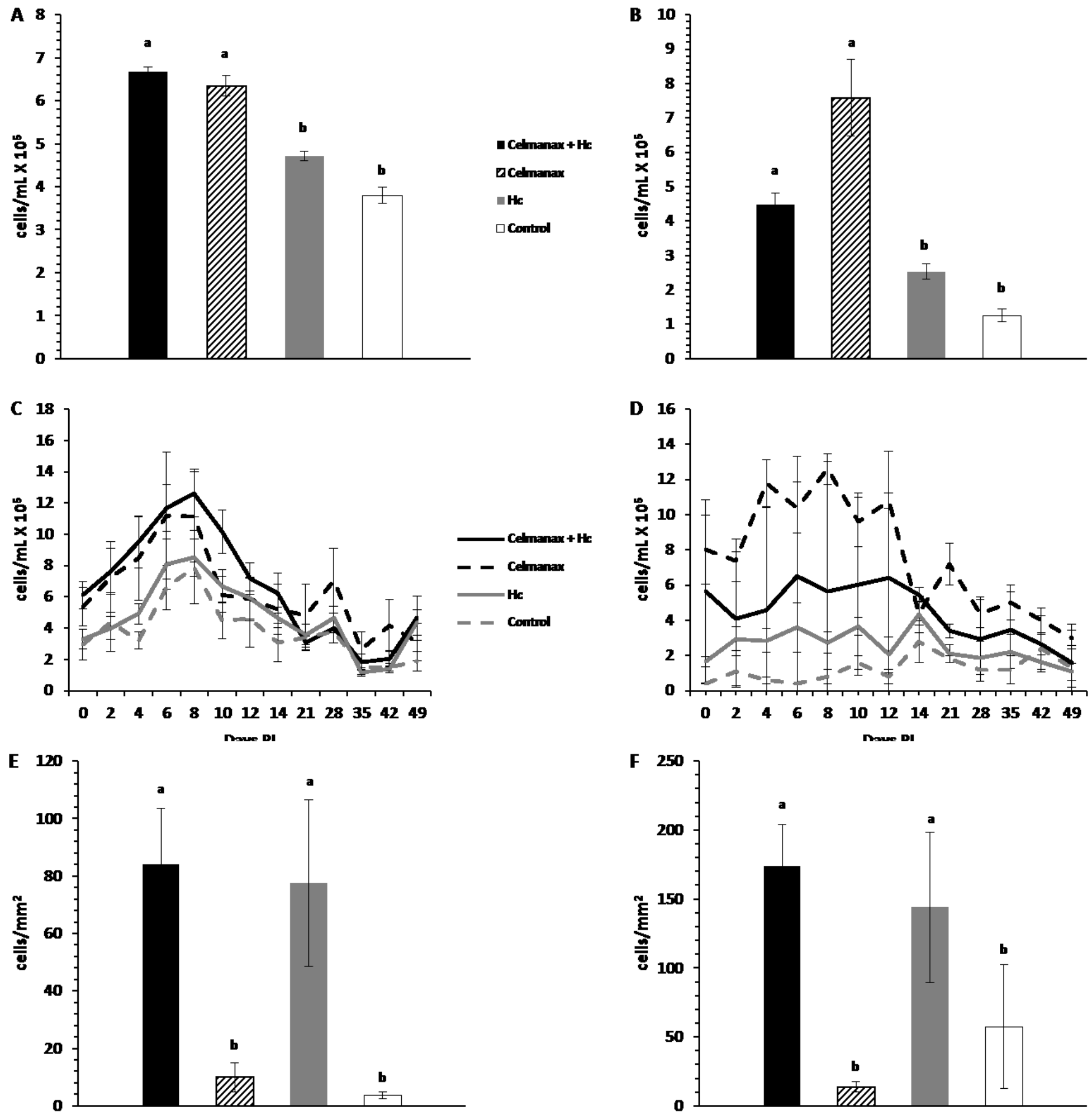

Figure 7. Eosinophil counts of lambs during primary and challenge $H$. contortus infections.

Circulating blood eosinophils were measured and averaged across all time points during primary $(A)$ and challenge (B) $H$. contortus infection and are reported by individual time points for primary $(\mathrm{C})$ and challenge (D) infection. At harvest, a section of the abomasum fundic region was fixed in formalin and stained with $\mathrm{H} \& \mathrm{E}$ and 40 non-sequential views were averaged to generate tissue eosinophil per square $\mathrm{mm}$ during primary $(\mathrm{E})$ and challenge $(\mathrm{F})$ infection. Error bars represent SEM. Means not connected by the same letter are significantly different at $<0.05$. 

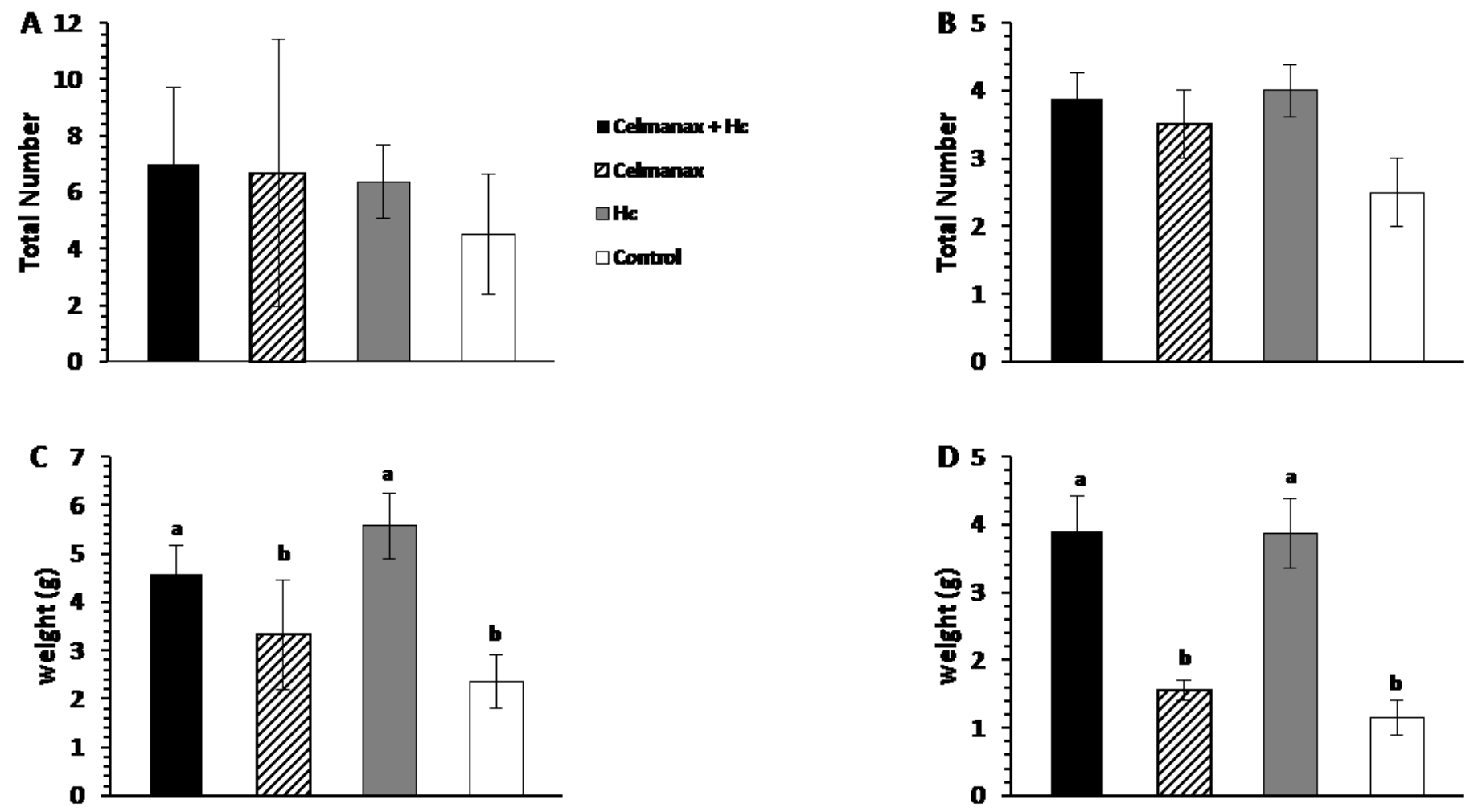

Figure 8. Lymph node counts and weights during primary and challenge $H$. contortus infections.

All palpable lymph nodes in the lesser curvature of the abomasum were counted during a primary (A) and challenge (B) infection. All palpable lymph nodes were weighed and averaged by treatment groups during primary $(C)$ and challenge (D) infection. Error bars represent SEM. Means not connected by the same letter are significantly different at $<0.05$. 

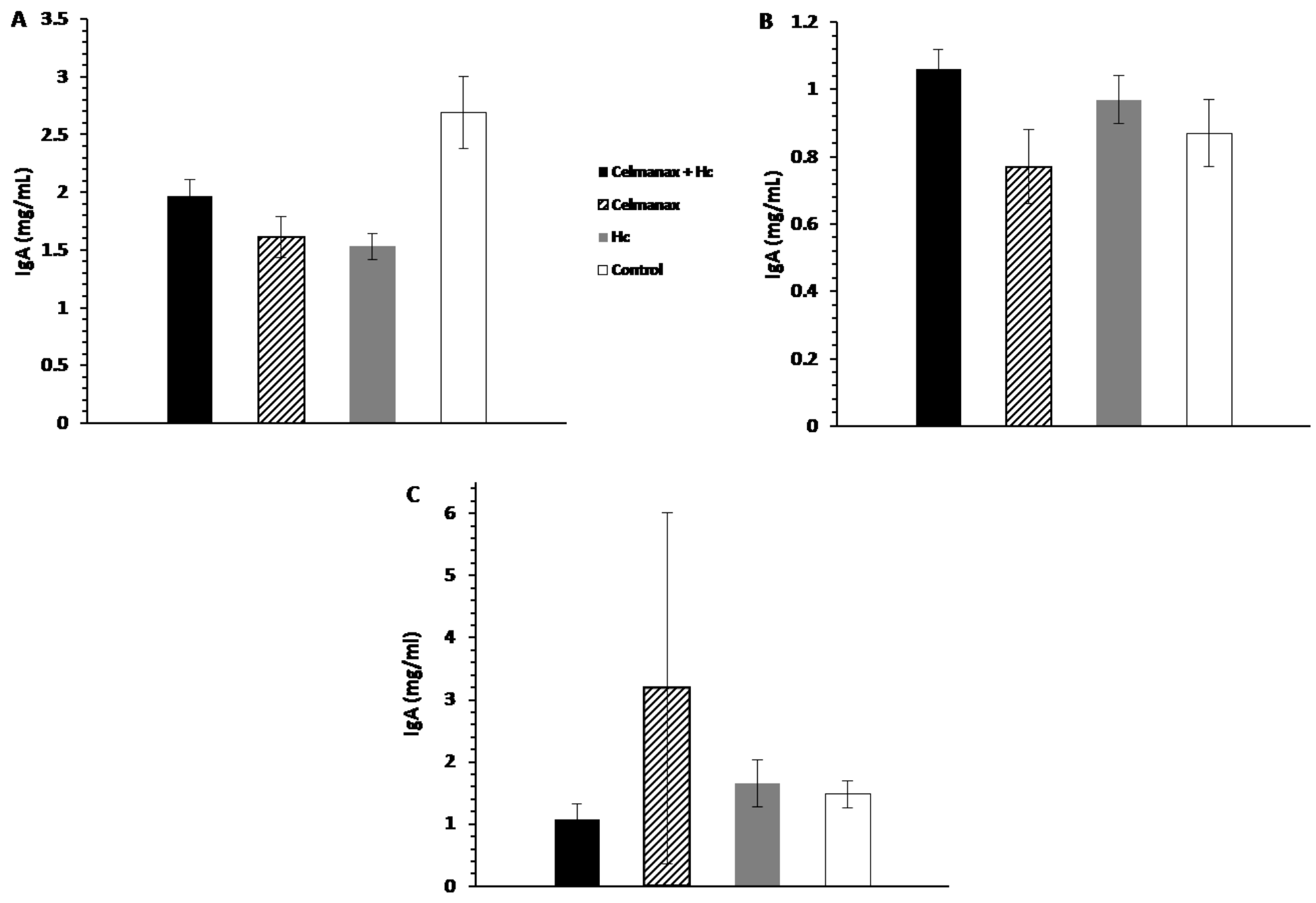

Figure 9. Serum and mucus IgA during $H$. contortus infections.

Serum IgA levels were averaged across all time points during primary $(A)$ and challenge $(B)$ infections. Upon harvest, mucus was collected from the abomasum and IgA was measured during a primary infection (C). Error bars represent SEM. 

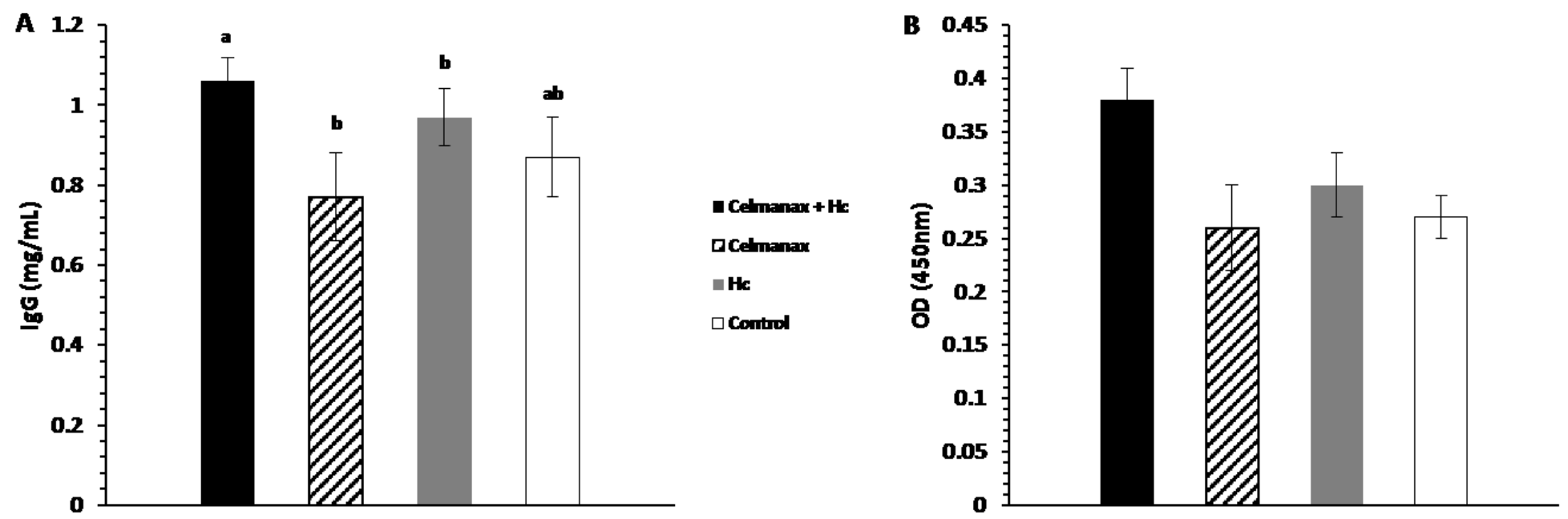

Figure 10. Serum and antigen specific IgG production during challenge $H$. contortus infection.

Circulating IgG was averaged across all time points (A). IgG specific for crude worm antigen (CWA) was measured at all time point and averaged for reporting (B). Errors bars represent SEM. Means not connected by same letter are significantly different at $<0.05$. 

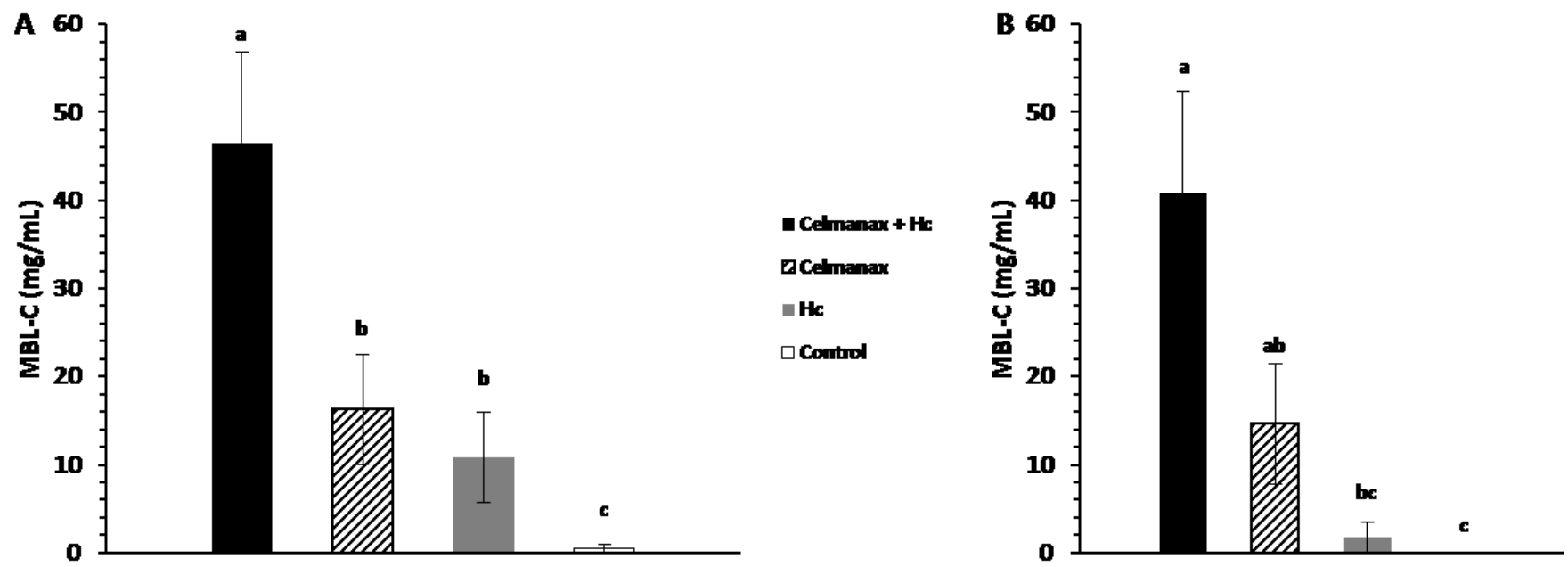

Figure 11. Production of serum Mannose Binding Lectin-C (MBL-C) during primary and challenge $H$. contortus infections.

Average across all time points, serum MBL-C was measured during primary infection $(A)$ and challenge infection (B). Error bars represent standard error. Means not connected by the same letter are significantly different at $<0.05$. 


\begin{tabular}{|lccc|}
\hline Gene: & $\frac{\text { Primary }}{\text { Infection }}$ & $\frac{\text { Challenge }}{\text { Infection }}$ & $\frac{\text { P-value }}{\text { IL-4R }}$ \\
IL-13 & $\downarrow$ (trt, inf) & ND & 0.05 \\
IL-5 & - & - & - \\
IL-10 & ND & - & - \\
IL-12 & ND & - & - \\
FOXP3 & ND & $\downarrow$ (inf) & 0.05 \\
GATA3 & ND & - & - \\
IFN-v & ND & $\downarrow$ (inf) & 0.01 \\
T-bet & ND & - & - \\
\hline
\end{tabular}

Table 3. Lymph node gene expression during primary and challenge $H$. contortus infections. 


\begin{tabular}{|lccc|}
\hline Gene & $\begin{array}{c}\text { Primary } \\
\text { Infection }\end{array}$ & $\begin{array}{c}\text { Challenge } \\
\text { Infection }\end{array}$ & P-value \\
ARG-1 & - & - & - \\
MRC-1 & - & - & - \\
iNOS & - & ND & - \\
IL-5 & - & ND & - \\
IL-6 & ND & - & - \\
IL-10 & - & - & - \\
IL-12 & ND & T (inf) & O.05 \\
IL-13 & - & - & - \\
IFN-Y & ND & - & - \\
IGF-1 & - & - & - \\
\hline
\end{tabular}

Table 4. Fundic mucosa gene expression during primary and challenge $H$. contortus infections. 


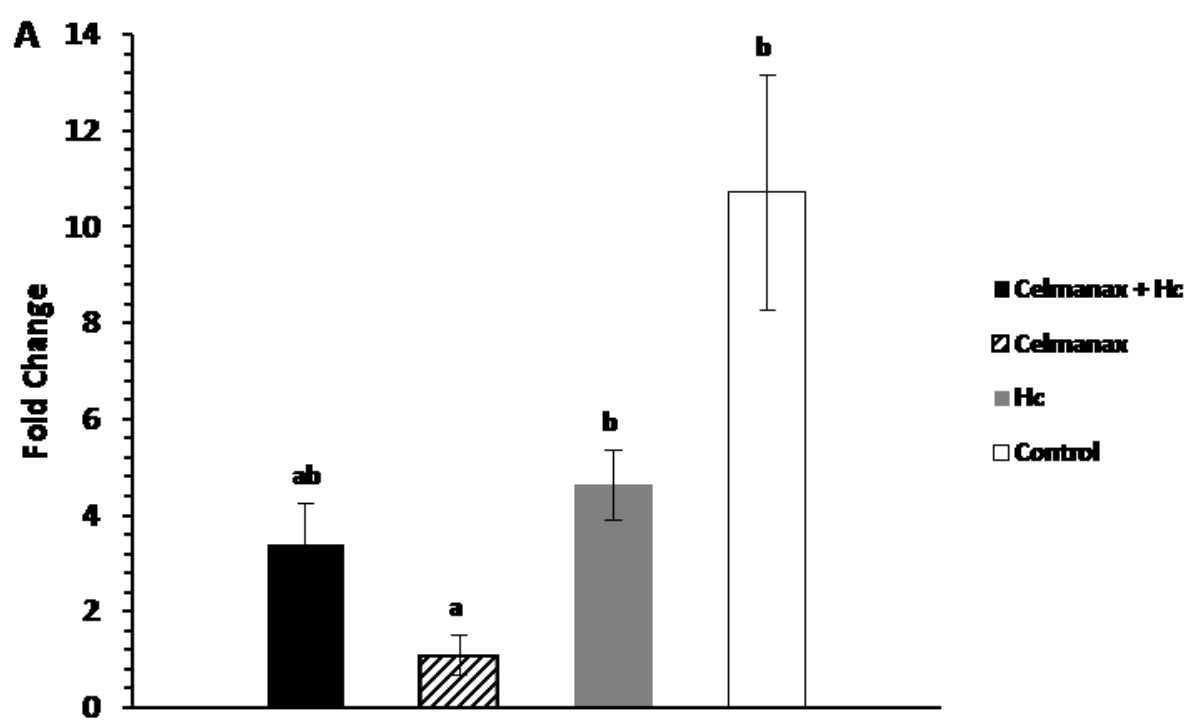

Figure 12. TNF- $\alpha$ gene expression in the fundic mucosa during a challenge $H$. contortus infection.

Fundic mucosa sample were collected upon harvest of lambs infected with $H$. contortus and analyzed for TNF- $\alpha$ gene expression. Error bars represent standard error. Means not connected by the same letter are significantly different at $<0.05$. 


\section{Literature Cited}

Abel, L. C, S. Chen, L. G. Ricca, M. F. Martins, M. Garcia, R. Z. Ananias, J. S.

Mussalem, C. C. Squaiella, R. J. Shaw, and I. M. Longo-Maugéri. 2009. Adjuvant effect of LPS and killed Propionibacterium acnes on the development of experimental gastrointestinal nematode infestation in sheep. Parasit.Immunol.31: 604-612.

Aerts, R. J., T. N. Barry, and W. C. McNabb. 1999. Polyphenols and agriculture beneficial effects of proanthocyanidins in forages. Agr. Ecosyst. Environ. 75: 112.

Amarante, A. F., T. M. Craig, W. S. Ramsey, N. M. El-Sayed, A. Y. Desouki, and F. W. Bazer. 1999. Comparison of naturally acquired parasite burdens among Florida native, Rambouillet and crossbreed ewes. Vet. Parasitol. 85: 61-69.

Andrews, S. J., N. J. Hole, E. A. Munn, and T. P. Rolph. 1995. Vaccination of sheep against haemonchosis with $\mathrm{H} 11$, a gut membrane-derived protective antigen from the adult parasite: prevention of the periparturient rise and colostral transfer of protective immunity. Int. J. Parasitol. 25: 839-846.

Anthony, R. M., J. F. Urban, F. Alem, H. A. Hamed, C. T. Rozo, J.L. Boucher, N. Van Rooijen, and W. C. Gause. 2006. Memory TH2 cells induce alternatively activated macrophages to mediate protection against nematode parasites. Nat. Med.12: 955-960.

Baines, D., S. Erb, R. Lowe, K. Turkington, E. Sabau, G. Kuldau, J. Juba, L. Masson, A. Mazza, and R. Roberts. 2011. A prebiotic, Celmanax ${ }^{\mathrm{TM}}$, decreases Escherichia coli $\mathrm{O} 157: \mathrm{H} 7$ colonization of bovine cells and feed-associated cytotoxicity in vitro. BMC Res. Notes 4: 110. 
Balic, A. , V. M. Bowles, and E. N. Meeusen. 2000a. Cellular profiles in the abomasal mucosa and lymph node during primary infection with Haemonchus contortus in sheep. Vet. Immunol. Immunopathol. 75: 109-120.

Balic, A., V. M. Bowles, and E. N. Meesen. 2000b. The immunobiology of gastrointestional nematode infections in ruminants. Adv. Parasitol. 45: 181-241.

Balic, A., V. M. Bowles, Y. S. Liu, and E. N. Meeusen. 2003. Local immune responses in sensitized sheep following challenge infection with Teladorsagia circumcincta. Parasit. Immunol. 25: 375-381.

Balic, A., Y. Harcus, M. J. Holland, and R. M. Maizels. 2004. Selective maturation of dendritic cells by Nippostrongylus brasiliensis-secreted proteins drives Th2 immune responses. Eur. J. Immunol. 34: 3047-3059.

Bambou, J.C., C. de la Chevrotière, H. Varo, R. Arquet, F. Kooyman, and N. Mandonnet. 2008. Serum antibody responses in Creole kids experimentally infected with Haemonchus contortus. Vet. Parasitol.158: 311-318.

Bishop, S. C., and C. A. Morris. 2007. Genetics of disease resistance in sheep and goats. Small Ruminant Res. 70: 48-59.

Bowdridge, S. 2009. Characterizing physiological and genetic differences in the early immune response to Haemonchus contortus in resistant and susceptible sheep. PhD Diss. Virginia Polytechnic Institute and State Univ., Blacksburg.

Bowman, D. 2009. Georgi's Parsitology for Veterinarians. 9 ed. Saunders Elsevier, St. Louis.

Burke, J. M., J. E. Miller, D. D. Olcott, B. M. Olcott, and T. H. Terrill. 2004. Effect of copper oxide wire particles dosage and feed supplement level on Haemonchus contortus infection in lambs. Vet.Parasitol.123: 235-243. 
Cerami, A., Y. Ikeda, N. Le Trang, P. J. Hotez, and B. Beutler. 1985. Weight loss associated with an endotoxin-induced mediator from peritoneal marcophages: the role of cachectin (tumor necrosis factor). Immunol. Lett. 11: 173-177.

Charbonnel, N., and J. Pemberton. 2005. A long-term genetic survey of an ungulate population reveals balancing selection acting on $\mathrm{MHC}$ through spatial and temporal fluctuations in selection. Heredity 95: 377-388.

Che, T. M., R. W. Johnson, K. W. Kelley, K. A. Dawson, C. A. Moran, and J. E. Pettigrew. 2012. Effects of mannan oligosaccharide on cytokine secretions by porcine alveolar macrophages and serum cytokine concentrations in nursery pigs. J. Anim. Sci. 90: 657-668.

Coltman, D. W., J. Pilkington, L. E. Kruuk, K. Wilson, and J. M. Pemberton. 2001. Positive genetic correlation between parasite resistance and body size in a freeliving ungulate population. Evolution 55: 2116-2125.

Czech, A., E. R. Grela, A. Mokrzycka, and Z. Pejsak. 2010. Efficacy of MOS additive to sows diets on colostrum, blood immunoglobulin content and production parameters of piglets. Pol. J. Vet.Sci.13: 525-531.

Datta, F. U., J. V. Nolan, J. B. Rowe, G. D. Gray, and B. J. Crook. 1999. Long-term effects of short-term provision of protein-enriched diets on resistance to nematode infection, and live-weight gain and wool growth in sheep. Int. J. Parasitol.29: 479-488.

Diez-Tascón, C., O. M. Keane, T. Wilson, A. Zadissa, D. L. Hyndman, D. B. Baird, J. C. McEwan, and A. M. Crawford. 2005. Microarray analysis of selection lines from outbred populations to identify genes involved with nematode parasite resistance in sheep. Physiol. Genomics 21: 59-69.

Dillon, S., S. Agrawal, K. Banerjee, J. Letterio, T. L. Denning, K. Oswald-Richter, D. J. Kasprowicz, K. Kellar, J. Pare, T. van Dyke, S. Ziegler, D. Unutmaz, and B. Pulendran. 2006. Yeast zymosan, a stimulus for TLR2 and dectin-1, induces 
regulatory antigen-presenting cells and immunological tolerance. J. Clin. Invest.116: 916-928.

Drudge, J. H., J. Szanto, Z. N. Wyant, and G. Elam. 1964. Field studies on parasite control in sheep: comparison of thiabendazole, ruelene, and phenothiazine. Amer. J. Vet. Res. 25: 1512-1518.

Esser-von Bieren, J., I. Mosconi, R. Guiet, A. Piersgilli, B. Volpe, F. Chen, W. C. Gause, A. Seitz, J. S. Verbeek, and N. L. Harris. 2013. Antibodies trap tissue migrating helminth larvae and prevent tissue damage by driving IL-4Ra-independent alternative differentiation of macrophages. PLOS Pathog .9.

Feagan, B. G., G. R. Greenberg, G. Wild, R. N. Fedorak, P. Paré, J. W. McDonald, R. Dubé, A. Cohen, A. H. Steinhart, S. Landau, R. A. Aguzzi, I. H. Fox, and M. K. Vandervoort. 2005. Treatment of ulcerative colitis with a humanized antibody to the alpha4beta7 integrin. New Engl. J. Med. 352: 2499-2507.

Fearon, D.T. , and K. F. Austen. 1977. Activation of the alternative complement pathway due to resistance of zymosan-bound amplification convertase to endogenous regulatory mechanisms. Proc. Natl. Acad. Sci. U.S.A. 74: 1683-1687.

Fuller, R. 1991. Probiotics in human medicine. Gut 32: 439-442.

Galdeano, C. M., and G. Perdigón. 2006. The probiotic bacterium Lactobacillus casei induces activation of the gut mucosal immune system through innate immunity. Clin.Vaccine Immunol.13: 219-226.

Gamble, H. R., and A. M. Zajac. 1992. Resistance of St. Croix lambs to Haemonchus contortus in experimentally and naturally acquired infections. Vet.Parasitol.41: 211-225.

Gibson, G. R., and M. B. Roberfroid. 1995. Dietary modulation of the human colonic microbiota: introducing the concept of prebiotics. J. Nutr.125: 1401-1412. 
Good, B., J. P. Hanrahan, B. A. Crowley, and G. Mulcahy. 2006. Texel sheep are more resistant to natural nematode challenge than Suffolk sheep based on fecal egg count and nematode burden. Vet. Parasitol. 136: 317-327.

Goodridge, H. S., R. M. Simmons, and D. M. Underhill. 2007. Dectin-1 stimulation by Candida albicans yeast or zymosan triggers NFAT activation in macrophages and dendritic cells. J. Immunol.178: 3107-3115.

Gordon, S. 2003. Alternative activation of macrophages. Nat. Rev. Immunol. 3: 23-35.

Gruner L., J. Bouix, J. Vu Tien Khang. 2004. A short-term divergent selection for resistance to Teladorsagia circumcincta in Romanov sheep using natural or artificial challenge. Genet. Sel. Evol. 36:217-242.

Hanan, F., M. Dalia, M. El-Dimerdash, D. Amina, and F. Eman.2012. Efficacy of synbiotic (Celmanax) in broilers vaccinated with Coccivac. Proc. 5th Sci. Conf. Ani. Wealth Res. M.E.N.A., Giza, Egypt.

Horton, G. M. J., and C. C. Burgher. 1992. Physiological and carcasscharacteristics of hair and wool breeds of sheep. Small Ruminant Res. 7, 51-60.

Howell, S. B., J. M. Burke, J. E. Miller, T. H. Terrill, E. Valencia, M. J. Williams, L. H. Williamson, A. M. Zajac, and R. M. Kaplan. 2008. Prevalence of anthelmintic resistance on sheep and goat farms in the southeastern United States. J. Am. Vet. Med. Assoc. 233: 1913-1919.

Huff, G. R., W. E. Huff, S. Jalukar, J. Oppy, N. C. Rath, and B. Packialakshmi. 2013. The effects of yeast feed supplementation on turkey performance and pathogen colonization in a transport stress/Escherichia coli challenge. Poultry Sci. 92: 655662.

Jia, W., L. Cao, S. Yang, H. Dong, Y. Zhang, H. Wei, W. Jing, L. Hou, and C. Wang. 2013. Regulatory $T$ cells are protective in systemic inflammation response syndrome induced by zymosan in mice. PloS ONE 8. 
Klasing, K. C., D. E. Laurin, R. K. Peng, and D. M. Fry. 1987. Immunologically mediated growth depression in chicks: influence of feed intake, corticosterone and interleukin-1. J. Nutr. 117: 1629-1637.

Lacroux, C., T. H. Nguyen, O. Andreoletti, F. Prevot, C. Grisez, J.P. Bergeaud, L. Gruner, J.C. Brunel, D. Francois, P. Dorchies, and P. Jacquiet. 2006. Haemonchus contortus (Nematoda: Trichostrongylidae) infection in lambs elicits an unequivocal Th2 immune response. Vet. Res. 37: 607-622.

Le Jambre, L. F., W. H. Southcott, K. M. Dash. 1976. Resistance of selected lines of Haemonchus contortus to thiabendazole, morantel tartrate and levamisole. Int. J. Parasitol. 6: 217-222.

Lee, Y.K., K.Y. Puong, A. C. Ouwehand, and S. Salminen. 2003. Displacement of bacterial pathogens from mucus and Caco-2 cell surface by lactobacilli. J. Med. Microbio. 52: 925-930.

Liang, J., D. Melican, L. Cafro, G. Palace, L. Fisette, R. Armstrong, and M. L. Patchen. 1998. Enhanced clearance of a multiple antibiotic resistant Staphylococcus aureus in rats treated with PGG-glucan is associated with increased leukocyte counts and increased neutrophil oxidative burst activity. Int. J. Immunopharmaco. 20: 595-614.

Livak, K. J., and T. D. Schmittgen. 2001. Analysis of relative gene expression data using real-time quantitative PCR and the 2(-Delta Delta C(T)) Method. Methods 25: 402-408.

Manning, T.S., and G.R. Gibson. 2004. Prebiotics. Best Prac. Res. Clin. Gasteroenterol. 108: 975-982

Malaczewska, J., and S. Milewski. 2010. Immunomodulating effect of Inter Yeast S on the non-specific and specific cellular and humoral immunity in lambs. Pol. J. Vet. Sci.13: 163-170. 
Miller, J. E., M. Bahirathan, S. L. Lemarie, F. G. Hembry, M. T. Kearney, and S. R. Barras. 1998. Epidemiology of gastrointestinal nematode parasitism in Suffolk and Gulf Coast Native sheep with special emphasis on relative susceptibility to Haemonchus contortus infection. Vet. Parasitol. 74: 55-74.

Mizuno, M., Y. Ito, N. Hepburn, T. Mizuno, Y. Noda, Y. Yuzawa, C. Harris, B. Morgan, and S. Matsuo. 2009. Zymosan, but not lipopolysaccharide, triggers severe and progressive peritoneal injury accompanied by complement activation in a rat peritonitis model. J. Immunol.183: 1403-1412.

Morimoto, M., M. Morimoto, J. Whitmir, S. Xiao, R. M. Anthony, H. Mirakami, R. A. Star, J. F. Urban, W. C. Gause. 2004. Peripheral CD4 T cells rapidly accumulate at the host:parasite interface during an inflammatory Th2 memory response. J. Immunol. 172: 2424-2430.

Mueller-Harvey, I., and A. B. McAllan. 1992. Tannins: Their biochemistry and nutritional properties. Adv. Plant Cell Biochem. Biotech.1.

Mugambi, J. M., R. K. Bain, S. W. Wanyangu, M. A. Ihiga, J. L. Duncan, M. Murray, and M. J. Stear. 1997. Resistance of four sheep breeds to natural and subsequent artificial Haemonchus contortus infection. Vet. Parasitol. 69: 265-273.

Nocek, J. E., M. G. Holt, and J. Oppy. 2011. Effects of supplementation with yeast culture and enzymatically hydrolyzed yeast on performance of early lactation dairy cattle. J. Dairy Sci. 94: 4046-4056.

NSIP. 2004. A breeder's guide to LAMBPLAN, Merino Genetic Selection and KIDPLAN. Accessed Sept. 25, 2013. http://www.nsip.org/wp-content/uploads/2012/06/ Breeders-Guide.pdf

Paolini, V., A. Frayssines, F. De La Farge, P. Dorchies, and H. Hoste. 2003. Effects of condensed tannins on established populations and on incoming larvae of Trichostrongylus colubriformis and Teladorsagia circumcincta in goats. Vet. Res. 34: 331-339. 
Paterson, K. A., J. C. McEwan, K. G. Dodds, C. A. Morris, and A. M. Crawford. 2001. Fine mapping a locus affecting host resistance to internal parasite in sheep. Proc. Assoc. Advmt. Anim. Breed. Genet. 14: 91-94.

Percival, S. S. 1998. Copper and immunity. Amer. J. Clin. Nutr. 67: 1064S-1068S.

Pernthaner, A., S.A. Cole, L. Morrison, R. Green, R. J. Shaw, and W. R. Hein. 2006. Cytokine and antibody subclass responses in the intestinal lymph of sheep during repeated experimental infections with the nematode parasite Trichostrongylus colubriformis. Vet.Immunol.Immunopath. 114: 135-148.

Quintin, J., S. Saeed, J. H. Martens, E. J. Giamarellos-Bourboulis, D. C. Ifrim, C. Logie, L. Jacobs, T. Jansen, B. J. Kullberg, C. Wijmenga, L. A. Joosten, R. J. Xavier, J. W. van der Meer, H. G. Stunnenberg, and M. G. Netea. 2012. Candida albicans infection affords protection against reinfection via functional reprogramming of monocytes. Cell Host Microbe 12: 223-232.

Reese, T. A., H. E. Liang, A. M. Tager, A. D. Luster, N. Van Rooijen, D. Voehringer, and R. M. Locksley. 2007. Chitin induces accumulation in tissue of innate immune cells associated with allergy. Nature 447: 92-96.

Reyes, J. L, and L. I. Terrazas. 2007. The divergent roles of alternatively activated macrophages in helminthic infections. Parasit. Immunol. 29: 609-619.

Rowe, J. B., J. V. Nolan, G. de Chaneet, E. Teleni, and P. H. Holmes. 1988. The effect of haemonchosis and blood loss into the abomasum on digestion in sheep. Brit. J. Nutr. 59: 125-139.

Sayers, G., B. Good, J. P. Hanrahan, M. Ryan, J. M. Angles, and T. Sweeney. 2005a. Major histocompatibility complex DRB1 gene: its role in nematode resistance in Suffolk and Texel sheep breeds. Parasitology 131: 403-409.

Sayers, G., B. Good, J. P. Hanrahan, M. Ryan, and T. Sweeney. 2005b. Intron 1 of the interferon gamma gene: its role in nematode resistance in Suffolk and Texel sheep breeds. Res. Vet. Sci. 79: 191-196. 
Schallig, H. D., M. A. van Leeuwen, and A. W. Cornelissen. 1997. Protective immunity induced by vaccination with two Haemonchus contortus excretory secretory proteins in sheep. Parasit.Immunol.19: 447-453.

Sel, S., M. Wegmann, S. Sel, S. Bauer, H. Garn, G. Alber, and H. Renz. 2007. Immunomodulatory effects of viral TLR ligands on experimental asthma depend on the additive effects of IL-12 and IL-10. J. Immunol. 178: 7805-7813.

Sewell, D., Z. Qing, E. Reinke, D. Elliot, J. Weinstock, M. Sandor, and Z. Fabry. 2003. Immunomodulation of experimental autoimmune encephalomyelitis by helminth ova immunization. Int.Immunol.15: 59-69.

Shakya, K. P., J. E. Miller, and D. W. Horohov. 2009. A Th2 type of immune response is associated with increased resistance to Haemonchus contortus in naturally infected Gulf Coast Native lambs. Vet.Parasitol.163: 57-66.

Shaw, R. J., C. A. Morris, R. S. Green, M. Wheeler, S. A. Bisset, A. Vlassoff, and P. G. C. Douch. 1999. Genetic and phenotypic relationships among Trichostrongylus colubriformisspecific immunoglobulin E, anti-Trichostrongylus colubriformis antibody, immunoglobulin $\mathrm{G} 1$, faecal egg count and body weight traits in grazing Romney lambs. Livest. Prod. Sci. 58: 25-32.

Terefe, G., C. Lacroux, O. Andreoletti, C. Grisez, F. Prevot, J. Bergeaud, J. Penicaud, V. Rouillon, L. Gruner, J. C. Brunel, D. Francois, J. Bouix, P. Dorchies, and P. Jacquiet. 2007. Immune response to Haemonchus contortus infection in susceptible (INRA 401) and resistant (Barbados Black Belly) breeds of lambs. Parasit. Immunol. 29: 415-424.

Thomas, R. J., and D. A. Ali. 1983. The effects of Haemonchus contortus infection on the pregnant and lactating ewe. Int. J. Parasitol.13: 393-398.

Tizard, I. 2013. Veterinary Immunology. 9 ed. Elsevier-Saunders, St. Louis.

Tzianabos, A. O. 2000. Polysaccharide immunomodulators as therapeutic agents: structural aspects and biologic function. Clin. Microbiol. Rev.13: 523-533. 
van Wyk, J. A., and F. S. Malan. 1988. Resistance of field strains of Haemonchus contortus to ivermectin, closantel, rafoxanide and the benzimidazoles in South Africa. Vet. Rec. 123: 226-228.

Wakshull, E., D. Brunke-Reese, J. Lindermuth, L. Fisette, R. S. Nathans, J. J.Crowley, J. C. Tufts, J. Zimmerman, W. Mackin, and D. S. Adams. 1999. PGG-glucan, a soluble beta-(1,3)-glucan, enhances the oxidative burst response, microbicidal activity, and activates an NF-kappa B-like factor in human PMN: evidence for a glycosphingolipid beta-(1,3)-glucan receptor. Immunopharmacology 41: 89-107.

White, T. R., R. C. Thompson, W. J. Penhale, and G .Chihara. 1998. The effect of lentinan on the resistance of mice to Mesocestoides corti. Parsitol. Res. 74: 563568.

Wildeus, S. 1997. Hair sheep genetic resources and their contribution to diversified small ruminant production in the United States. J. Anim. Sci.75: 630-640.

Wilson, K. H., and F. Perini. 1988. Role of competition for nutrients in suppression of Clostridium difficile by the colonic microflora. Infect.Immun. 56: 2610-2614. 